\title{
The relationship between plasma osmolarity and feed efficiency in beef cattle and effect of feeding cows medicated feed through mineral containing AltosidRTM IGR on the growth of beef calves
}

Taylor Diane Harrison

Follow this and additional works at: https://researchrepository.wvu.edu/etd

\footnotetext{
Recommended Citation

Harrison, Taylor Diane, "The relationship between plasma osmolarity and feed efficiency in beef cattle and effect of feeding cows medicated feed through mineral containing AltosidRTM IGR on the growth of beef calves" (2016). Graduate Theses, Dissertations, and Problem Reports. 5773.

https://researchrepository.wvu.edu/etd/5773
}

This Thesis is protected by copyright and/or related rights. It has been brought to you by the The Research Repository @ WVU with permission from the rights-holder(s). You are free to use this Thesis in any way that is permitted by the copyright and related rights legislation that applies to your use. For other uses you must obtain permission from the rights-holder(s) directly, unless additional rights are indicated by a Creative Commons license in the record and/ or on the work itself. This Thesis has been accepted for inclusion in WVU Graduate Theses, Dissertations, and Problem Reports collection by an authorized administrator of The Research Repository @ WVU. For more information, please contact researchrepository@mail.wvu.edu. 
The relationship between plasma osmolarity and feed efficiency in beef cattle and effect of feeding cows medicated feed through mineral containing Altosid ${ }^{\circledR}$ IGR on the growth of beef calves

Taylor Diane Harrison

Thesis submitted to the Davis College of Agriculture, Natural Resources and Design at West Virginia University in partial fulfillment of the requirements for the degree of

Master of Science in Animal Physiology

Eugene E. Felton, Ph.D., Chair

Scott A. Bowdridge, Ph.D.

Kevin S. Shaffer, Ph.D.

Division of Animal and Nutritional Sciences

Morgantown, West Virginia

2016

Keywords: RFI, Blood Osmolarity, Beef Cattle, Feed Efficiency

Copyright 2016 Taylor Diane Harrison 


\begin{abstract}

\section{Relationship between plasma osmolarity and feed efficiency in beef cattle}

\title{
Taylor Diane Harrison
}

Dietary cation-anion modification in cattle has effects on productivity through various means. Alterations of dietary cation-anion balances has been shown to affect plasma osmolarity. Plasma osmolarity is directly related to renal function and metabolism in all animals. In a feeding operation with a single diet fed to a similar population of animals, plasma osmolarity should fall within a somewhat normal range (approximately $270-310 \mathrm{mOsm}$ ). However, subtle, yet very distinguishable differences will exist between animals. In theory, variances in osmolarity may reflect differences in metabolism and as such, efficiency of feed utilization. Many researchers believe that utilizing residual feed intake (RFI) expressed in a population as a selection tool will lead to improved production efficiency in beef cattle. Residual feed intake is normally distributed. Like osmolarity, RFI will have subtle, yet very distinguishable differences existing between animals. The objective of this study is to determine if there are any detectable relationships between plasma osmolarity measurements and RFI within a controlled test population and to further determine how this information may be used in improving the utility of RFI measurements. In this study (77d), intake, BW, and ultrasound measurements of yearling heifers were observed. Frozen $\left(-60^{\circ} \mathrm{C}\right)$ plasma samples were thawed at room temperature and osmolarity determined. Plasma samples $(n=67, n=70)$ were analyzed to determine osmolarity. All data were analyzed using the CORR procedures of SAS. Plasma osmolarity measured on day 70 demonstrated a weak relationship to RFI $(\mathrm{r}=0.226 ; P=0.0)$; no other correlations existed $(P$ $>0.10)$ in this data set. There were little to no relationships between osmolarity and ultrasound rump fat $(P>0.90)$, rib fat $(P>0.98)$ and intramuscular fat $((P>0.13)$. Only days 21 and 35 had relationships between ribeye area and osmolarity. $(P=0.04 ; P=0.0002)$. There were also minimal detectable relationships of osmolarity with metabolic body size $(P>0.06)$ or intake $(P$ $>0.08$ ). However, osmolarity values fluctuated over the nine (year 1 ) or ten (year 2 ) different time points, thus plasma osmolarity measurements taken during or shortly after dietary adaptation may not directly correlate to an animal's RFI value. However, analysis of how animals establish a cation-anion balance may have some relationship to the animals RFI phenotype. 


\section{Acknowledgements}

First and foremost, to my four legged friends you are forever my inspiration. I'd like to thank my tandem of advisors, Dr. Bowdridge and Dr. Felton, for their patience and willingness throughout my graduate career. I would not be here today if it weren't for Dr. Bowdridge. He brought me here to coach the livestock judging team, which has proved to be a challenging, but very rewarding endeavor. Although, not my major advisor, he has always been there to help any way he can, whether it be with my team or with research. Dr. Felton, thank you for your patience when I am gone on the road and for always being in my corner. Without your support, I would not have made it this far. Both of you have expanded my horizons in ways I cannot begin to explain in words, but I am so grateful. You two have always pushed me to be more and although at the time I didn't see the benefit, I know it made me a better person in the long run.

These past three years, would not have been possible without all the support I received. Crista Crawford, Javi Garza, Jesica Jacobs, Denzel Middleton, Brynnan Russ, Elizabeth Shepherd and Melissa Wise, thank you for always being supportive lab mates of this crazy cow girl. Additionally, thank you to Dr. Barnes and Dr. Gartin for always allowing me to not only invade your office and vent, but for believing in me and my judging program. It means so much to me.

Lastly, but certainly not least, thank you to my family and friends (Pepperanne and Nancy, this includes you too). Graduate school was always in the plans, but I had no idea I would end up here, let alone coaching a judging team. To my friends who always picked up the phone after a hard day, thank you for supporting me no matter what. To my Mom and Dad, thank you for always giving me the opportunity to chase my dreams and for always believing in me. I truly have the best parents in the world and I couldn't have done it without you guys. I love you. 


\section{Contents}

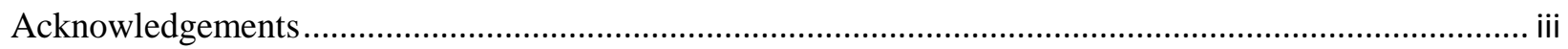

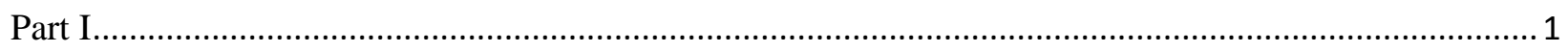

Section 1: Literature Review................................................................................................ 1

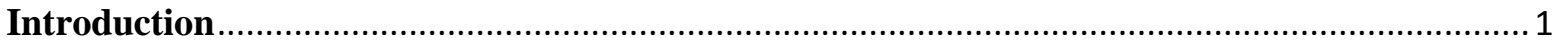

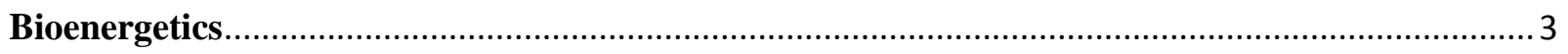

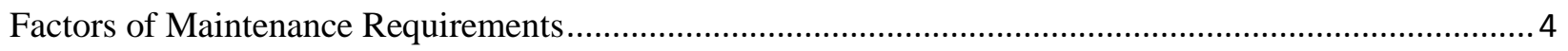

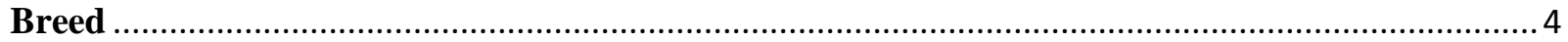

Sex

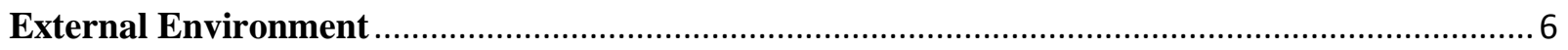

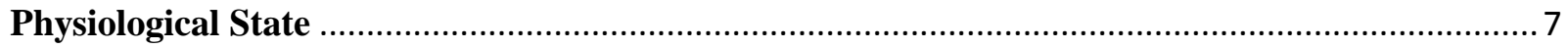

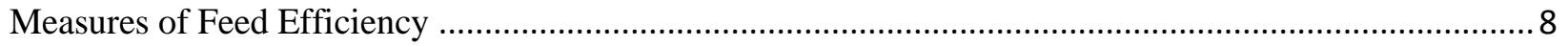

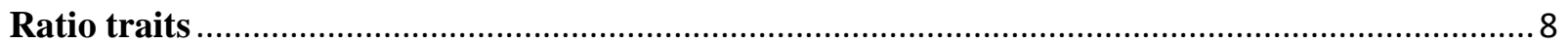

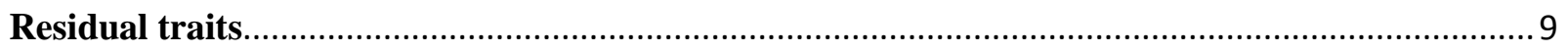

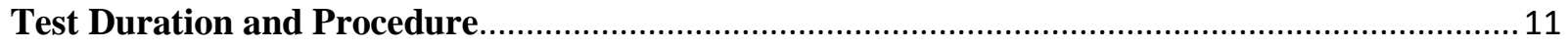

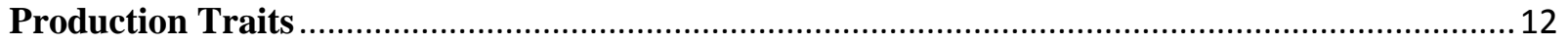

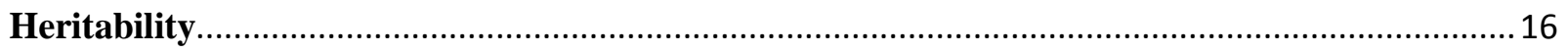

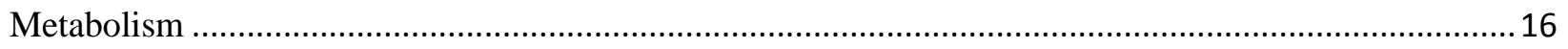

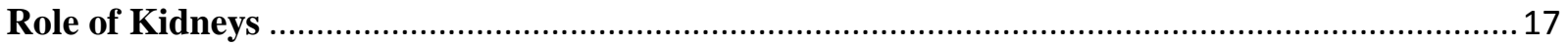

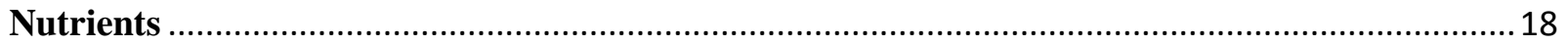

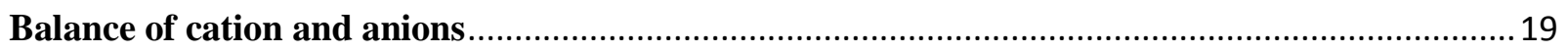

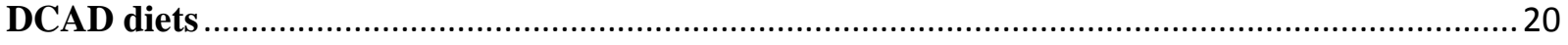

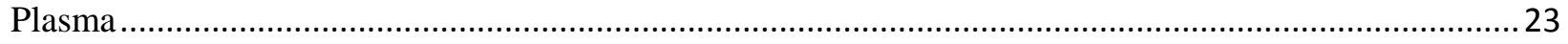

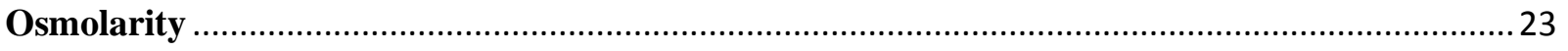

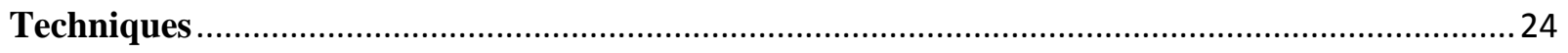

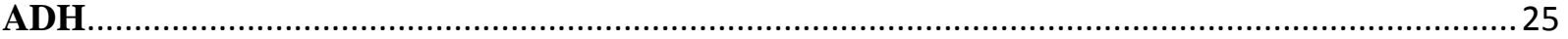

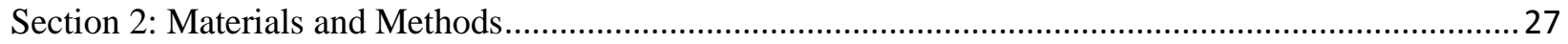

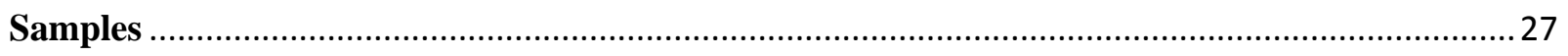

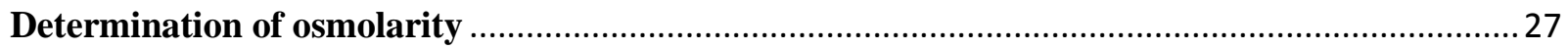

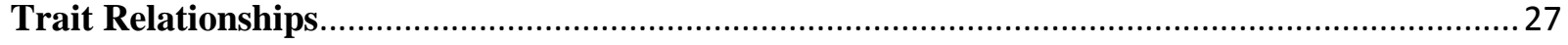

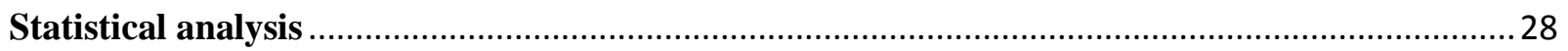

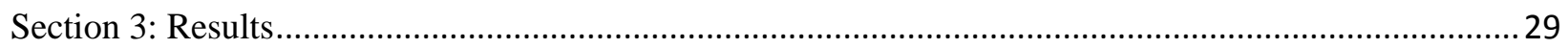




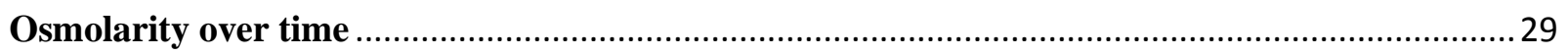

Determination of relationships between osmolarity and carcass traits ......................................29

Determination of relationships between osmolarity and production traits ..................................29

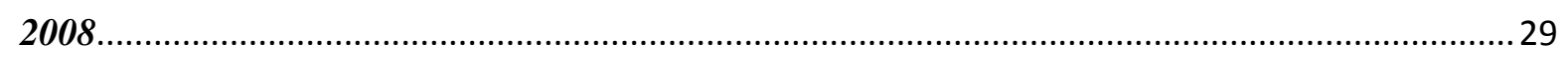

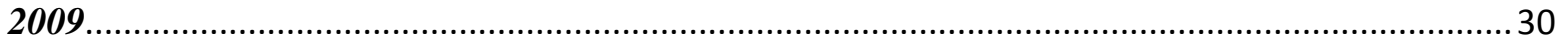

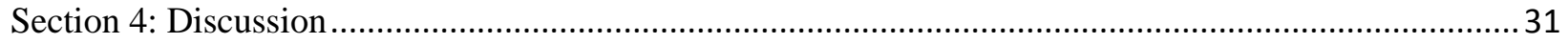

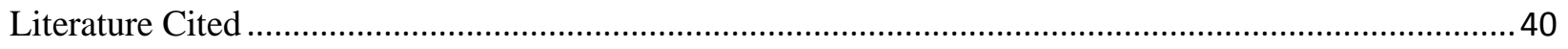

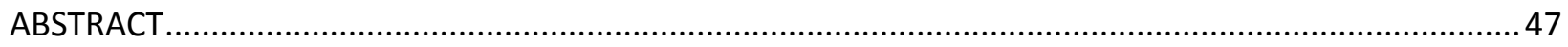

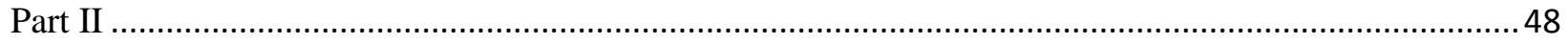

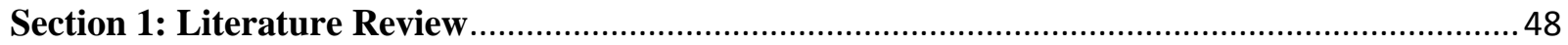

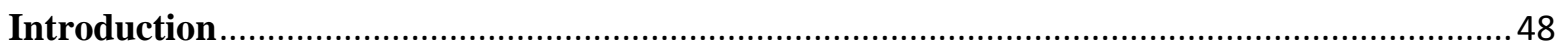

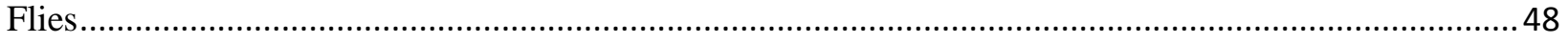

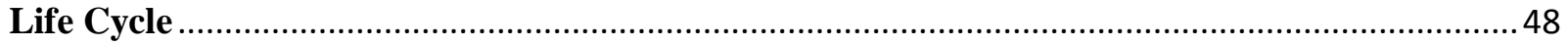

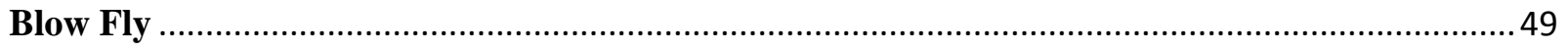

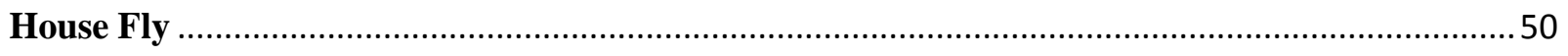

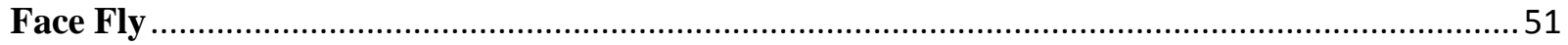

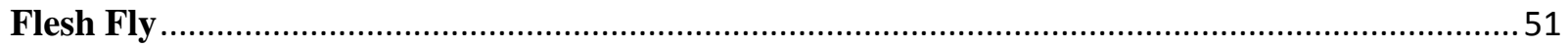

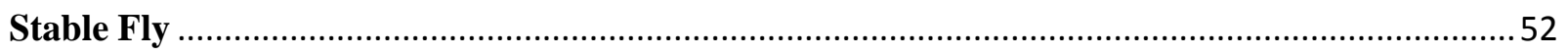

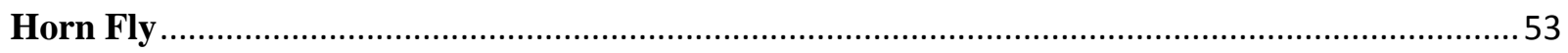

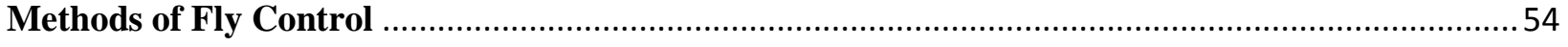

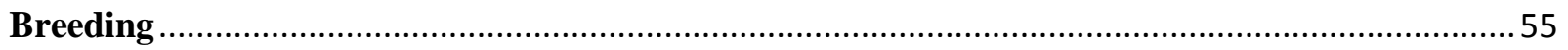

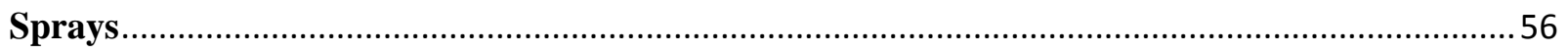

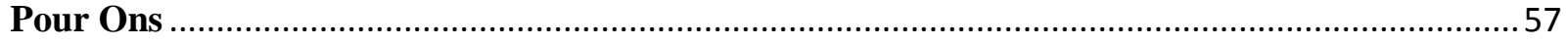

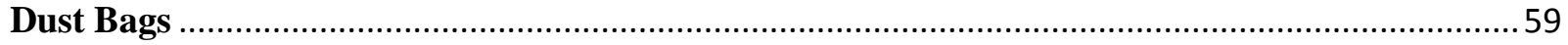

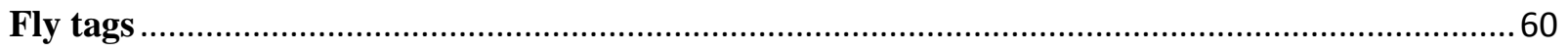

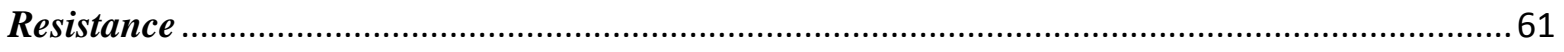

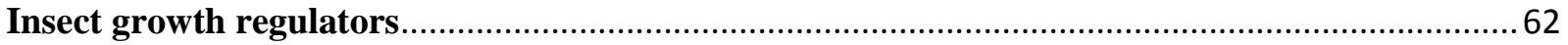

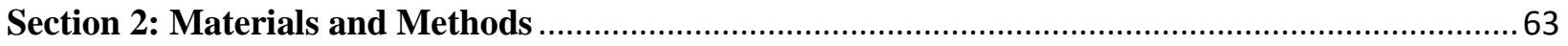

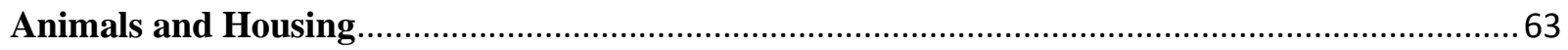

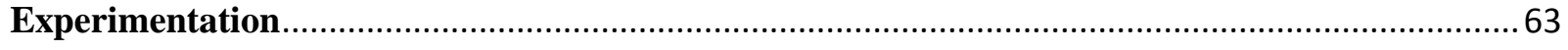

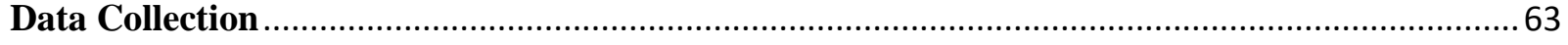

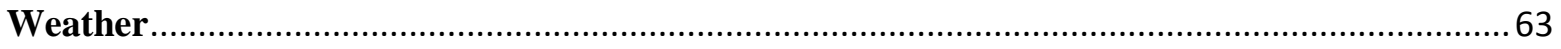




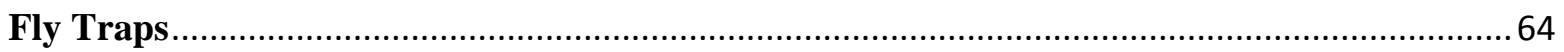

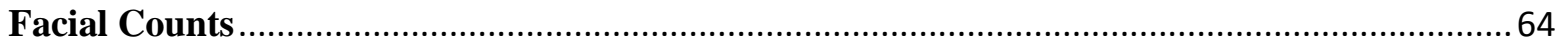

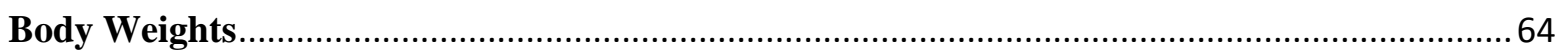

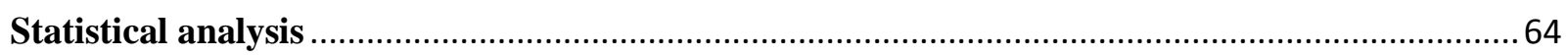

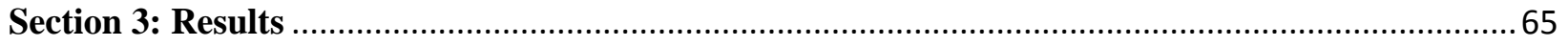

Weather

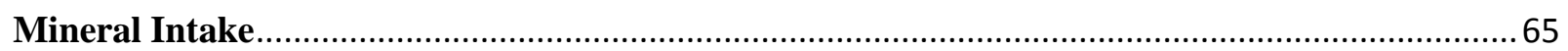

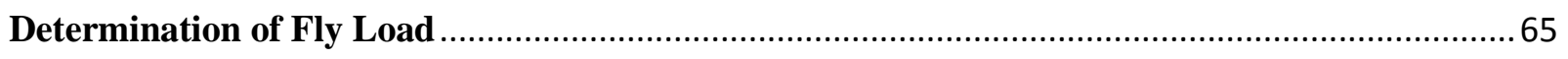

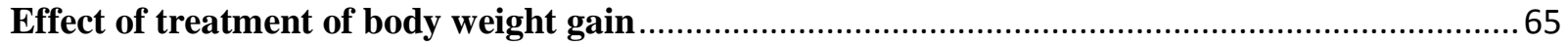

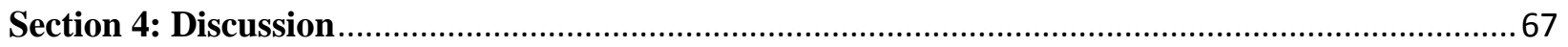

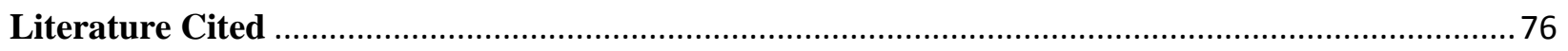




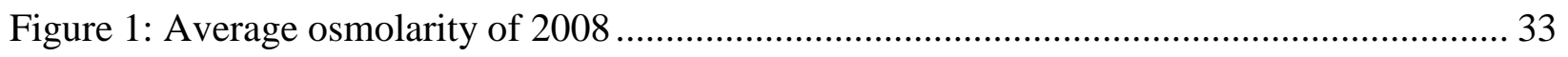

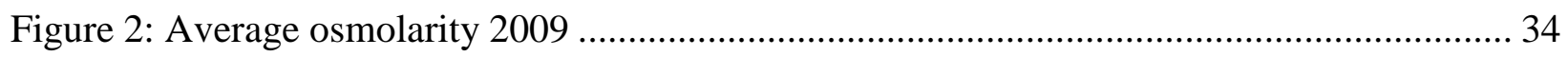

Figure 3. Fly species determined by fly traps analyzed by date .......................................... 70

Figure 4. Fly species determined by fly traps for each treatment type.................................. 71

Figure 5. Facial fly counts for cows of the three treatment groups based on photography........ 72

Figure 6. Facial fly counts for calves of the three treatment groups based on photography. ....... 73

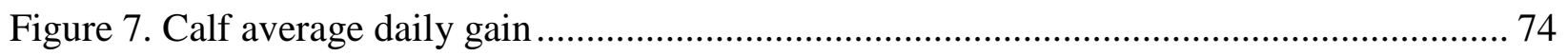

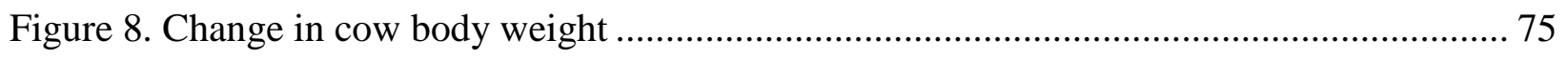


Table 1: Pearson correlations between osmolarity and carcass traits 2008 35

Table 2: Pearson correlations between osmolarity and production traits 2008 36

Table 3: Pearson correlations between osmolarity and production traits 2009 37

Table 4: Pearson correlations between osmolarity and RFI by group 2008 .38

Table 5: Pearson correlations between osmolarity and RFI by group 2009 39 


\section{Part I}

\section{Section 1: Literature Review \\ Introduction}

In recent times the beef industry has been faced with greater economic challenges due to an increasing human population, biosecurity issues and the search for alternative "healthy" food selections. The majority of high energy feedstuffs previously readily available to feed cattle will be less accessible as resources continue to be used elsewhere. Heavy utilization of feed resources elsewhere has increased feed costs thus reducing potential profitability. These factors have caused a rise in annual production costs as the livestock industry contributes $\$ 714$ to $\$ 739$ million to annual external agricultural costs (Tegtmeier and Duffy, 2011).

Historically, producers tried to improve profitability through improvement in production traits instead of decreasing production costs (Sainz. et al., 2004). The focus of genetic improvement has been aimed on traits such as fertility and live weight with little emphasis placed on traits reducing inputs (Archer et al., 2001). This strategy led to an increase in mature body size and subsequently increased feed intake (Herd and Bishop, 2000). Furthermore, onesided genetic selection lead to animals with not only increased feed requirements, but higher feed costs, higher heat production, as well as higher emissions and manure production ultimately leading to a potential increased environmental impact (Luiting et al., 1994). For these reasons, it is imperative that the beef industry identifies alternative ways to increase profitability by minimize input costs.

It has been reported that providing feed to cattle is the largest single expense in beef production enterprises. Approximately $70 \%$ of all total costs are in fact attributed to feed (Herd et al., 1999, Arthur et al., 2001). Of the feed being consumed it is has been shown that about 70 
to $75 \%$ of total energy requirements are used solely for maintenance functions (Ferrell and Jenkins, 1985). Of those energy requirements needed for beef production, at least 60 to $65 \%$ is utilized by the cow herd. (Gregory, 1972). This demonstrates that roughly one-half of production costs can be linked to maintenance requirements. Thus, taking into account the impact feed expenses have on profitability, improved feed efficiency has been targeted as a way to increase profitability. There are many potential methods to measure feed efficiency such as feed:gain, gain:feed, protein efficiency ratio and residual feed intake. However, many of measures have a potential negative consequence when used as a selection tool.

Ratio traits by definition are not independent measures, however, residual feed intake is (Koch et al., 1963). Residual feed intake has been shown to be independent of factors that affect maintenance and gain. It has been reported that RFI is one of the principal biological economic traits (Koots and Gibson, 1998). Therefore, selection using RFI can not only improve efficiency, but more significantly have the potential to improve profitability. Technology needed to calculate RFI can be very costly and the amount of time needed can be lengthy. It is challenging to find a sole aspect responsible for efficiency because there are many factors that have an influence on efficiency. Koch et al. (1963) reported that $38 \%$ of the variation in gain could be attributed to genetic differences in feed efficiency. Genetic differences in feed consumption accounted for $25 \%$ of the variation in gain, and the remaining $37 \%$ of the variation in gain was accounted for by variations in environmental influences. Variation in efficiency can be attributed to five major processes: intake of feed, digestion of feed, metabolism, body composition activity and thermoregulation (Herd et al. 2004). One could argue that metabolism can and will impact each of other four processes and is the component that is the least well described in regards to its contribution to efficiency. Given the known role that plasma osmolites like $\mathrm{Na}^{+}, \mathrm{K}^{+}, \mathrm{Mg}^{+}$and $\mathrm{Cl}^{-}$ 
have in affecting metabolism through processes such as energy generation and muscle function and their clearance/regulation through renal function. The focus of this literature review will be on the factors affecting feed efficiency in beef cattle, RFI and plasma osmolarity.

\section{Bioenergetics}

In order to effectively understand feed efficiency, it is critical to understand the biological processes of feed utilization. All physiological processes utilize energy released by breaking high energy phosphate bonds. Phosphoanhydride high energy bonds release a large amount of free energy due to hydrolysis. These bonds are generated through the exchange of dietary energy. The reaction of adenosine triphosphate (ATP) with water transforms ATP into adenosine diphosphate (ADP) and inorganic phosphate $\left(\mathrm{P}_{\mathrm{i}}\right)$. Free energy change associated with this reaction drives cellular reactions (Milo and Phillips, 2015). In the past it was challenging to quantify dietary energy values utilized by each animal. However, Lofgreen and Garrett (1968) proposed the California Net Energy System, which describes how dietary gross energy can be broken down into two subgroups of either energy loss or retention, as determined using comparative slaughter methods. This system accounts for losses from gross energy in feces, urine, methane and heat, then separates dietary energy needs into two classes: maintenance or gain. Maintenance is defined as the feed energy $\left(\mathrm{NE}_{\mathrm{m}}\right)$ required for zero body energy change or feed energy required for zero body weight change. (Ferrell and Jenkins, 1985). Whereas, energy utilized for productive functions above maintenance $\left(\mathrm{NE}_{\mathrm{g}}\right)$ is considered gain as there is a net gain in whole body energy. This system is widely accepted today and commonly used in the evaluation of feedstuffs and ration formulation.

As reported by Ferrell and Jenkins (1985), maintenance compromises a majority of energetic requirements. Approximately $70 \%$ of the metabolizable energy requirement of mature beef cows is used solely for maintenance purposes. In mature bulls, at least $90 \%$ of the energy 
requirement is needed to satisfy maintenance requirements. There are many different factors that account for variation in maintenance requirements and include; breed, sex, environment and physiological state can all contribute to variation among individual maintenance requirements. Given the degree in which these factors affect maintenance requirements it is imperative to discuss the factors influencing this requirement. These factors are discussed in the following sections.

\section{Factors of Maintenance Requirements}

\section{Breed}

Dated back to as early as 1911, Armsby and Fries, noted that there was an energetic efficiency difference between Angus and Jersey influenced steers, with the Angus steer being more efficient. Klosterman et al. (1968) and Turner et al. (1974) reported that efficiency of cows is independent of breed and generally more related to body size. The greatest factor affecting maintenance requirement in both studies was body condition. Lemenager et al. (1980) also found in a study complied of late gestation and early gestation cows that weight alone cannot accurately predict energy requirements of cows. Marshall et al. (2001) found that weight or condition only accounted for less than $1 \%$ of variation in efficiency in Angus, Charolais and crossbred cows. Whereas, milk production alone contributed $23 \%$ to variation in efficiency. According to Ferrell and Jenkins (1980), terminal breeds, such as Simmental and Charolais required more dry matter intake than maternal based crossbreds such as Angus x Hereford and Jersey cross cows based on extended feeding trials. Likewise, mature, open, nonlactating Simmental cows required $16.1 \%$ more metabolizable energy (ME) for maintenance than Angus cows of similar status. 
In a study with dry, open cows of five different breeds; Angus, Brahman, Hereford, Holstein and Jersey, it was found that maintenance requirements for weight and energy equilibrium were lower in beef breeds and their crosses as Angus, Brahman and Hereford all had similar requirements; $91.6,93.8$ and $95.3 \mathrm{kcal} / \mathrm{BW}^{0.75}$, respectively. While dairy breeds (Holstein and Jersey) were significantly higher, 115.7 and 140.4 kcal/BW ${ }^{0.75}$ (Solis et al., 1988). Similar results were also discovered by Ferrell and Jenkins, (1971) and Montano-Bermudez et al., (1990).

Maintenance requirements also differ between Bos indicus and Bos taurus cattle. According to the NRC (2000), Bos indicus breeds of cattle require about 10\% less energy for maintenance than Bos taurus breed, with crossbreds being intermediate. Additionally, it is apparent that differences between body composition and physiological priorities between beef and dairy breeds significantly influence maintenance requirements and efficiency of energy use (Solis et. al, 1988). These data indicate that maintenance requirements differ based on breed.

\section{Sex}

Ray et al. (1969) found in a feedlot performance study of that steers gained more rapidly and efficiently than heifers in a feedlot scenario $(P<0.05)$. Ferrell and Jenkins, $(1980)$ found a 16.5\% difference in ME required for Simmental bulls versus heifers. However, there was only a 2\% difference between Hereford bulls and heifers in the same study. Kloosterman and Parker (1976) found steers had slightly higher daily feed intake and gained faster than heifers. However, on a weight basis per day, the heifers consumed more dry matter and were fatter at a final weight $(385 \mathrm{~kg})$ than steers $(453 \mathrm{~kg})$. When comparing steers and heifers both fed $1.5 \mathrm{x}$ maintenance, heifers had lower $(P<0.025)$ ME requirements than steers (Hotovy et al., 1991). This conclusion was not supported by Chizzotti et al. (2007) as they found the net energy of maintenance to be similar $(P=0.06)$ between $36 \mathrm{~F}_{1}$ Nellore $\mathrm{x}$ Red Angus calves (12 bulls, 12 heifers and 12 steers). 
This discrepancy may be a result of the sample size ( $\mathrm{n}=36)$. The NRC (2000) suggests that intact bulls have maintenance requirements greater than that of castrated males. Furthermore, data indicate that intact males can have up to $16 \%$ greater maintenance requirements than steers or heifers, with heifers having the lowest requirement for maintenance.

\section{External Environment}

Ruminants interact with their outside environment through exchange of necessary components for living such as oxygen and carbon dioxide. Environmental conditions impact physiological state of the animal as the body tries to maintain homeostasis. The body's ability to maintain a proper body temperature is part of that homeostasis. Ruminants have a thermoneutral zone in which no net energy is expended in the maintenance of body temperature. Heat production is a function of feed intake and efficiency (Arthur and Herd, 2009). When the ambient temperate moves outside the thermoneutral zone, energy must be expended either in the generation or dissipation of heat. Nutritional needs of the cow change during heat stress, and need ration reformulation to account for decreased DMI, the need to increase nutrient density, changing nutrient requirements, avoiding nutrient excesses and maintenance of normal rumen function is necessary (West, 2003). Robinson et al. (1986) conducted a study using twelve Hereford x Red Angus yearling steers, four steers were assigned to each of the following three different environments; cold $\left(3^{\circ} \mathrm{C}\right)$, thermoneutrality $\left(\mathrm{TNZ} ; 20^{\circ} \mathrm{C}\right)$ and heat $\left(35^{\circ} \mathrm{C}\right)$. Heat production was determined after 3 and 24 hours. Heat production was greater for the coldacclimated cattle $\left(139.6 \pm 5.0\right.$ and $\left.153.0 \pm 5.8 \mathrm{kcal} \cdot \mathrm{kg}^{-75} \cdot \mathrm{d}^{-1}\right)$ as compared to TNZ-acclimated cattle $\left(117.7 \pm 5.0\right.$ and $\left.121.6 \pm 5.8 \mathrm{kcal} \cdot \mathrm{kg}^{-.75} \cdot \mathrm{d}^{-1}\right)$. This change in metabolism would increase the nonshivering component of heat production and reduce the contribution of shivering during cold exposure. Reduced shivering associated with acclimation to cold may lead to reduced convective heat loss and increased animal comfort when cold-acclimated animals are exposed to cold 
conditions. However, a wasteful expenditure of energy would occur on those occasions when cold-acclimated cattle are exposed to thermoneutral conditions. Both of these actions cause an increase in metabolic rate thus coinciding to an increase in maintenance requirements. Ames and Brink (1977) conducted a study analyzing performance and protein efficiency ratio with lambs reared at various ambient temperatures, $-5,0,5,10,15,20,30$ and $35^{\circ} \mathrm{C}$. Temperature significantly affected average daily gain (ADG) and protein efficiency ratio $(P>0.01)$. Four trials were conducted, two in the hot summer months and two during moderate winter months for feedlot cattle. It was found that gains were 14 and $24 \%$ greater in the winter months and feed requirements were reduced by 7 and $19 \%$. Thus, it was determined from this study that high summer temperatures are major factors limiting feedlot performance of beef cattle (Ray et al. 1969).

\section{Physiological State}

Differences in physiological states are most easily seen with females. Energy inputs are required for maintenance, growth, gestation and lactation. Adequate energy is required for each of these functions to ensure the desired level of output (Moustgaard, 1969; Richardson et al., 1975). Brody (1945) stated that overall heat production increases during gestation. Graham (1964) observed a similar response in sheep where it was determined that $10 \%$ of maintenance requirements in ewes during pregnancy was due to fetal development. Furthermore, daily energy utilization by the conceptus at term accounted for approximately $70 \%$ of glucogenic substances from feed. These data were further supported in several experiments demonstrating that Holstein cows in the final 75 days of pregnancy require $75 \%$ more ME than nonpregnant cows (Moe and Tyrell, 1972). Additionally, Moe et al. (1972) reported that the amount of ME required for pregnant cows increases from $101 \mathrm{kcal} / \mathrm{kg}^{3} / 4$ on the first day of pregnancy to about $175 \mathrm{kcal} / \mathrm{kg}^{3} / 4$ at term. A series of studies were initiated in 1979 to develop a better understanding of energy 
utilization in mature females of different states during the production cycle. Ferrell and Jenkins (1981) evaluated maintenance requirements of nonpregnant, nonlactating mature cows and reported ME requirements of ranging from $129-160 \mathrm{kcal} \bullet \mathrm{kg}^{-.3 / 4} \bullet \mathrm{d}^{-1}$, respectively. Furthermore, pregnant, lactating cows were found to have higher requirements than both the previous groups. This finding is supported by Neville (1974) who found that lactating cows require $38-41 \%$ more ME for maintenance. Patle and Mudgal (1977) found similar results noting a 32.9\% difference between cows in early lactation and nonlactating cows for required ME for maintenance. The large energy expenditure by lactating cows is a result of changes in the amount of hormones produced, differences in voluntary activity, food intake, mastication and transport of food (Crampton \& Harris, 1969; Leroy, 1970).

\section{Measures of Feed Efficiency}

There are many different ways to measure feed efficiency. Efficiency values are characteristically recorded and determined during a performance test or defined feeding trials and often reported on per pen basis. Feed efficiency values are traditionally described as ratio traits. Ratio traits can lead to misinterpretation as similar ratios can result although input numbers may differ.

\section{Ratio traits}

Feed conversion ratio (FCR) was the most commonly used measure of feed efficiency in beef cattle. Feed conversion ratio (feed:gain) is defined as daily dry matter intake (DMI) divided by average daily gain (ADG) (Brody, 1945). Feed conversion ratio is highly correlated to feed intake and rate of gain of an animal. Thus, FCR includes feed inputs needed to support maintenance and growth requirements with no separation for either. Feed conversion expression is preferred gain: feed, however, results can still be misleading as ratios are closely related to 
intake and rate of gain (Carstens et al., 2004). This means that two animals may have a similar feed:gain, but actually have different feed intakes and rates of gain (Sainz et al., 2004). For example, an animal that consumes less feed and also has a slower rate gain may have the same feed to gain ratio as an animal that has a greater intake and a faster rate of gain.

An additional efficiency ratio commonly used is partial efficiency of growth (PEG). Partial efficiency of growth is the efficiency of growth after accounting for maintenance energy requirements and may be calculated as ADG divided by average feed intake not including feed intake required for maintenance. Maintenance requirements are estimated using feed tables (NRC, 1996) and average BW during the measurement period. Similar to FCR, PEG assumes differences in maintenance efficiency which is not always true (Archer et al., 1999). Thus this method is not the most accurate method in determining feed efficiency as relationships can lead to misleading conclusions. Additionally, selection for this ratio can lead to increased growth size and mature weight. Klieber (1947) described efficiency as daily weight gain per unit of metabolic body weight $\left(\mathrm{BW}^{0.75}\right)$, as known as the Klieber ratio. Fitzhugh and Taylor (1971) measured feed efficiency as it relates to maintenance and growth. The drawback with ratios such as these is that requirements for maintenance and growth must be accounted for. Additionally, the ratios are not distrubted equally as the denominator has a greater weight influence on overall ratio. Currently feed efficiency is described through a residual trait.

\section{Residual traits}

Residual feed intake (RFI) was first proposed by Koch et al. (1963) where metabolic body weight $\left(\mathrm{BW}^{0.75}\right)$ and average daily gain (ADG) was regressed against animal daily intake within a set population. When the difference in regression-determined intake is calculated based on actual intake, the value generated is residual feed intake or RFI. This trait predicts individual 
feed intake and quantifies efficiency as the residual between the actual and predicted value. Genetic variation has been noted in cattle both in the growth phase and at maintenance (Koch et al., 1963; Hoque et al., 2009; Richardson et al., 2004; Herd et al., 2000; Herd et al., 2004). Additonally, RFI is independent of size and growth (Crews, 2005), therefore, selection using RFI will not result in an increase in mature cow size. Advantages for utilizing RFI as a selection tool have indicated that selection for lower RFI measured postweaning will lead to a decrease in feed intake by young cattle and by cows, with no compromise in growth performance or increase in cow size (Herd et al., 2003). This is ultimately more profitable for the producer as larger framed animals require more feed resources. Thus, RFI should be a more sensitive and precise measurement of feed utilization.

Residual feed intake (RFI) is defined as the difference between an animal's actual feed intake and expected feed intake to needed for maintenance of body weight and production (Arthur et al., 2001). Koch et al. (1963) suggested that feed intake could be adjusted for bodyweight and gain (or any production trait) by effectively partitioning feed intake into two components: (1) the feed intake expected for the given level of production; and (2) a residual portion. The residual portion can be used to identify which animals deviate from their expected feed intake (Arthur et al., 2008). Animals that are more efficient will have lower (negative) values. The computation of RFI requires estimation of expected feed intake and can be predicted using feed standards formula (NRC, 1996), or by regression using actual feed test data (Kennedy et al., 1993; Arthur et al., 2001b). Likewise, RFI reported in several studies (Archer et al., 1997;

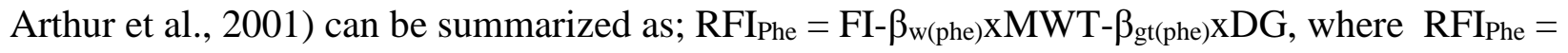
phenotypic residual feed intake, FI = daily feed intake, MWT = metabolic body weight at mid test, $\mathrm{DG}=$ average daily gain and $\beta_{\mathrm{w}(\mathrm{phe})}$ and $\beta_{\mathrm{gt}(\mathrm{phe})}=$ partial regression coefficients of animal's 
FI on MWT and DG (Hoque et al. 2009). The independence of RFI from production has led some authors to suggest that RFI may represent inherent variation in basic metabolic processes which determine efficiency (Athur et al., 2008; Brelin and Brannang, 1928; Korver, 1988).

Testing for RFI requires measurement over a defined period of time and usually occurs during a standard performance test. Feed intake and utilization of feed involves many biological processes and environmental influences; therefore, these factors must be controlled. Factors that affect feed intake include; age a start of test, sex, diet composition and testing procedures (Arthur and Herd, 2008).

\section{Test Duration and Procedure}

Based on the literature, test duration ranges from 35 - 84 days. This range exists as tests of shorter length primarily measured feed intake, whereas longer tests were measuring efficiency or a multitude of traits. Additionally, the increase in test duration was influenced by cattle of different biological types, as well as the type of system used to measure traits. Archer et al. (1997) recommended a test duration of 35 days for feed intake and 70 days for feed efficiency. These values for efficiency are supported by Archer and Bergh (2000) and recommended 70-84 days to calculate RFI for cattle of multiple biological types. Likewise, a study conducted using Angus and Hereford (representing British breeds), Simmental (European breed representation), Afrikaner (Bos Taurus) and Bonsmara (composite) cattle determined residual variances were established after 70 days for the Afrikaner, Angus and Bonsmara. However, RFI was established after 84 days for the Simmental and Hereford. Additionally, in this particular study daily feed intake response was found to have little variation thus shortening the test duration to 49 days supporting the previous statement that fewer days are needed to measure feed intake. Shortening of test duration may result in only minor losses in accuracy. Additionally, variances in intake for 
sires were determined after 49 days for all breeds except Afrikaner which took 56 days to establish (Arthur and Herd, 2000). Other recommended testing length from literature included 112 days (McPeake and Buchanan, 1986; Franklin et al. 1987; Kemp, 1990), 84 days (Swiger and Hazel, 1961; Liu and Makarechian, 1993a,b) and a 70 day test period with animals being weighed at least every 2 weeks was sufficient for a feed efficiency performance test (Archer et al., 1997). Studies that recommend 112 days generally base conclusions on phenotypic correlations with tests of shorter days ( 84 or 70 days) based on variance components. More recently, Wang et al. (2005) determined that 82.6 and 69.5 days were needed for testing on British and Continental bulls respectively. Additionally, 63, 35, 42 and 63 days were needed to calculate ADG, DMI, FCR and RFI, respectively (Wang et al., 2006). These studies were conducted using different diets, however literature suggests dietary effect is unlikely as Archer et al. (2007); Archer and Bergh (2000); Wang et al. (2005 and 2006) used a variety of feedstuffs. Kearney et al. (2004) used automatic weighing of animals to record BW while animals were feeding to try and reduce the amount of test days. However, the increase in BW records only reduced the duration of the test period for RFI to 56 days. In conclusion, there is no set standard for the number of days needed for RFI determination, but approximately 56-84 days is sufficient to measure RFI and can be influenced by biological and system types.

\section{Production Traits}

Residual feed intake is a relatively independent trait with minimal or no negative impact on production traits. This cannot be stated for other measures of efficiency. In particular, FCR as selection based on this trait can have a major impact on other production traits. Production traits characteristically of importance in the beef industry include; feed efficiency, growth traits, carcass trait and reproductive traits. With that being said, RFI is correlated with FCR, with 
correlation coefficients ranging from 0.45 to 0.85 . This indicates that improvement in RFI will result in an improvement in FCR (Arthur et al., 2001a,b; Schenkel et al., 2004; Robinson and Oddy, 2004; Hoque et al., 2006a; Nkrumah et al., 2007a). Additionally, RFI and feed intakehave a positive correlation indicating that animals more efficient will have a low RFI and consume less feed. By definition, RFI is independent of metabolic body weight and ADG and this holds true at a genetic level as indicated by the absence of significant correlation (Arthur and Herd, 2008). Genetic correlations between RFI and other growth traits, such as weaning and yearling weights are also close to zero. Arthur et al. (2001a) reported correlations near zero after accounting for standard error, direct and maternal effects. Additonally, Hoque et al. (2006) and Richardson et al. (1998) noted that steers of low RFI parents grew faster than steers of high RFI parents. Thus, postweaning RFI is genetically independent of mature cow weight (Herd and Bishop, 2000; Archer et al., 2002; Arthur et al., 2005). This further supports the case for using RFI as a selection tool. This does not hold true for other efficiency traits such, as correlations between FCR and ADG were reported to be moderate and negative (Arthur et al., 2001a.b; Schenkel et al., 2004). Therefore, selecting for animals with a low FCR are likely to produce offspring with a high mature weight increasing maintenance costs.

Reports on correlations between carcass traits and RFI vary greatly. Arthur et al. (2001a) and Robinson and Oddy (2004) both showed that RFI is either not associated or very weakly associated with ribeye area (REA). However, Nkrumah et al. (2007a) reported a low to moderate correlation between RFI and REA. Similarly, Arthur et al. (2000b) reported a positive correlation $(\mathrm{r}=0.14)$ between RFI and back fat observed on weaned bulls and heifers. This was supported by Basarab et al. (2003) where RFI was reported to be positively correlated $(\mathrm{r}=0.15)$ with ultrasounded backfat recorded at the end of the test on hybrid steers. However, RFI and 
backfat by ultrasound had a stronger association when taken during the testing period $(\mathrm{r}=0.22)$. Similarly, Robinson and Oddy (2004) reported correlations ( $r=0.48)$ for rump and rib fat with RFI recorded from one and two year old steers ( 0.72 and 0.48 adjusted for age; 0.79 and 0.58 adjusted for carcass weight). Few published reports describe a relationship between RFI and carcass weights and of those reported there is tremendous variability. Correlations between RFI and carcass weight (CWT) range from $-0.60 \pm .32$ to $0.05 \pm 0.38$ (Hoque et al., 2006 and Nkrumah et.al 2007). Jensen et al. (1991) noticed that increases in dressing percentage were associated with lower RFI values. It also appears that relationships between RFI and carcass traits may differ between breeds ofc attle. Arthur et al. (2001a) reported a correlation of $0.17 \pm 0.05$ between RFI and rib fat thicknesses in Angus bulls and heifers. Herd and Bishop (2000) reported a correlation of $-0.43 \pm 0.23$ between RFI and carcass lean content in Hereford bulls. It is worth noting in these studies the method of measuring marbling was different and the standard errors were large. Additionally, Hoque et al. (2006) reported that downward RFI selection of sires would lead to an increase in marbling score, ribeye area and subcutaneous fat thickness in their progeny. Correlations of RFI to marbling and subcutaneous fat of bulls on their progeny were negative; suggesting selection against RFI of bulls may have contributed to an increase in marbling and subcutaneous fat of progeny carcasses. Moreover, selection for decreased RFI may increase carcass fatness, presumably resulting from an independent relationship of RFI and time needed to raise animals to slaughter weight. These results suggest that there are commonly weak associations between RFI and carcass traits. However, the magnitude of association may be affected by age, sex and diet of test animals.

To achieve maximum profitability, animals also need to be feed efficient and reproductively sound. Blair et al. (2013) found no relationship between RFI and pregnancy rate, 
calving percentage and calving day $(P>0.10)$. Shaffer et al. (2011) found for every 1-unit increase in RFI there was a 7.5 day decrease in age at puberty $(P<0.05)$. Yet, no effect on pregnancy or conception rates was detected $(\mathrm{P}>0.10)$. However, heifers sired by efficient RFI bulls tended to have an improved calving rate in their second parity $(P>0.10)$. Arthur et al. (2005) studied 185 Angus cows across 3 mating seasons. Cows were the result of 1 to 2.5 generations of selection (mean of 1.5), and differed in estimated breeding value for residual feed intake by $0.8 \mathrm{~kg} / \mathrm{day}$. There were no significant selection line differences in pregnancy (mean of $90.4 \%$ ), calving (mean of $88.7 \%$ ) and weaning (mean of $80.8 \%$ ) rates, milk yield (mean of 7.7 $\mathrm{kg} / \mathrm{day}$ ) and weight of calf weaned per cow exposed to bull (mean of $195 \mathrm{~kg}$ ). This study indicates that after 1.5 generations of divergent selection for residual feed intake there are no significant selection line differences for maternal productivity traits. In addition, a study using Angus $(n=92)$, Bonsmara $(n=62)$, and Santa Gertrudis $(n=50)$ cattle analyzed scrotal circumference (SC), sperm motility and morphology. Only sperm morphology was found to be weakly associated with RFI (0.13). These data indicate that RFI is not phenotypically associated with SC or sperm motility but is weakly associated with sperm morphology (Hafla et al., 2012). Similarly, Wang et al. (2012) observed that breeding soundness exam (BSE) traits were not different $(\mathrm{P}>0.10)$ between bulls categorized as either inefficient (+RFI) or efficient (-RFI). However, in a subpopulation of 115 bulls, individual progressive sperm motility was greater $(\mathrm{P}<$ $0.05)$ in + RFI $(85 \%)$ than $-\mathrm{RFI}(80 \%)$ bulls. A multi-sire natural mating experiment was conducted during 2 consecutive breeding seasons (2006 - 2007 and 2007 - 2008) using $18+$ RFI and 18 -RFI bulls. The overall calving rate (calves born/cows exposed) was $72.9 \%$ and the mean number of progeny per sire was significantly greater $(\mathrm{P}<0.01)$ in $-\mathrm{RFI}$ bulls $(18.3)$ than in $+\mathrm{RFI}$ 
bulls (11.8). Thus, selection for feed efficiency based on RFI has no detrimental impact on reproductive performance and fertility in beef bulls bred in multi-sire groups on pasture.

\section{Heritability}

Genetic and phenotypic properties of residual feed intake are predictable from genetic and phenotypic parameters of its component traits, under normal assumptions. Kennedy et al. (1996) developed formulas to obtain genetic parameters of residual feed intake from knowledge of genetic and phenotypic parameters of component traits. Genetic parameters of residual feed intake were determined for a range of heritabilities $(\mathrm{h} 2=0.1,0.3$, or 0.5$)$ for component traits of feed intake and production traits, and genetic $\left(r_{g}=0.1,0.5\right.$, or 0.9$)$ and environmental $\left(r_{e}=0.1\right.$, 0.5 , or 0.9 ) correlations between them. Heritability reported of residual feed intake ranged from 0.03 to 0.84 and the genetic correlation between residual feed intake and production ranged from -0.90 to 0.87 . Similarly, Herd and Bishop (2000) noted heritability from 540 progeny of 154 British Hereford sires, collected over ten 200-day postweaning performance tests conducted over an eight year period. Residual feed intake was heritable (0.16, S.E. 0.08). Crews (2005) reported that heritability estimates for phenotypic residual feed intake have been moderate, ranging from 0.26 to 0.43 . Genetic correlations of phenotypic residual feed intake with feed intake have been large and positive suggesting that improvement would produce a correlated response of decreased feed intake. Residual feed intake estimated by genetic regression results in a genetic correlation of zero with its predictors, which reduces concerns over long-term antagonistic responses such as increased mature size and maintenance requirements (Crews, 2005).

\section{Metabolism}

Along with diverse biological processes, efficiency of feed utilization also includes feed intake, digestion and metabolic efficiency of the absorbed nutrients (Simeone et al., 2005). As 
described by Herd et al. (2004), variation can be attributed five major processes: intake of feed, digestion of feed, metabolism, body composition activity and thermoregulation. The contribution of each proposed mechanism was also reported: $9 \%$ for heat increment from digestion, $10 \%$ from digestibility, $10 \%$ from activity, 5\% from body composition, $2 \%$ from feeding patterns, $37 \%$ from protein turnover, metabolism and stress and $27 \%$ from other. Although, there are multiple mechanisms that make up efficiency this demonstrates that the largest component of efficiency is metabolism. Therefore, using metabolism efficiency can be better understood.

Metabolism is the term used to describe all chemical processes that occur in order to maintain a living organism. These processes can be categorized either by catabolism, the breakdown of materials to obtain energy and anabolism, the synthetization of molecules which requires energy. Both energy generation and utilization involves exchange (both active and passive) of mineral ions across membranes and through ionic pumps found embedded within membranes. These minerals are commonly defined as either cations or anions based on their charge and are ultimately regulated by renal function.

\section{Role of Kidneys}

Kidneys are traditionally known as the organ that excretes waste, but they also perform a spectrum of other essential function such as absorbing metabolites. Therefore, the kidneys must discriminate between what to keep and what to discard. Our bodies continuously form end products of metabolic processes. In most cases, those end products are of no use to the body and are harmful at high concentrations. Therefore, they must be excreted at the same rate as they are produced. Water, salt, and other electrolytes enter our bodies at highly variable rates, all of which perturb the amount and concentration of those substances in the body. The kidneys vary their excretion of electrolytes and water to preserve appropriate levels in the body. In doing so 
they maintain balance that is match output to input so as to keep a constant amount in the body. Metabolic waste products, ingested substances, and excess salt and water are constantly being removed from the body by a number of means, including disposal in the urine and feces, biochemical transformation in the liver, and exhalation. The rate of removal can be expressed in several ways, a common one being plasma half-life. Another way to express removal rate is clearance, which is the volume of plasma per unit time from which all of a specific substance is removed. For example, suppose each liter of plasma contains $10 \mathrm{mg}$ of a substance $\mathrm{X}$, and $1 \mathrm{mg}$ of substance $\mathrm{X}$ is excreted in 1 hour. Then $0.1 \mathrm{~L}$ of plasma supplies the $1 \mathrm{mg}$ that is excreted, and the renal clearance is $0.1 \mathrm{~L} / \mathrm{h}$.

These metabolic waste products are filtered from the blood by nephrons. Nephrons are composed of a glomerulus and tubule that drain the filtrate into the pelvis. The glomerular filtration system consists of endothelial cells, glomerular base membrane and visceral epithelial cells. Molecules then pass through this system where a countercurrent system forms a high osmotic gradient that concentrates the filtrate. The epithelial cells reabsorb water, proteins, amino acids, carbohydrates and electrolytes thus regulating plasma osmolarity and acid-base and electrolyte balance. Molecules and compounds that are not absorbed pass out of the system where they are excreted as urine (Kurts et al. 2013).

\section{Nutrients}

Requirements for maintenance and production of the major nutrients; protein, carbohydrate, fat, vitamins and minerals have been well defined. Sub-divisions of these major classes have been defined by nutritionists in order to more precisely determine nutrient needs. Most of these major classes can be defined by three or four subclasses allowing it to be relatively easy to study interactions amongst nutrients. However, this is not the case with minerals. 
Minerals are divided into two classes: macrominerals or microminerals. This is based on the quantities at which the minerals are found in the body. Minerals or ions, play a more crucial role than any other nutrient as they have their hand in many biological functions such as; expression and regulation of genes, enzyme systems, osmotic balance, detoxication and acid-base balance (Block, 1994). Of minerals in the body, sodium and chloride together account for $80 \%$ of normal extracellular solute; thus excretion of sodium and water by kidneys regulates osmolality in a tight range that is needed for the tissue cells health (Eaton and Pooler, 2013).

\section{Balance of cation and anions}

In balancing rations, fixed ions play a major role in acid-base balance. Fixed ions are ions that are not metabolized, $\mathrm{Na}+\mathrm{K}+$ and $\mathrm{Cl}-$. Sulphur is sometimes included as a fixed ion; however $\mathrm{S}$ is not actually a fixed ion because sulfates can directly acidify fluids. However, dietary cation-anion difference (DCAD) is defined as milliequivalents of $\left(\mathrm{Na}^{+}+\mathrm{K}^{+}\right)-\left(\mathrm{Cl}^{-}+\mathrm{S}^{-}\right)$ per kilogram of dry matter (DM). This has a direct impact on acid-base metabolism. Although, there are other minerals that play a role in acid-base metabolism, the four minerals used in DCAD have the greatest impact. The anions $\mathrm{Cl}^{-}$and $\mathrm{S}^{-}$should be balanced in a ration against cations, $\mathrm{Na}^{+}$and $\mathrm{K}^{+}$, to maximize animal functions. This balance is primarily achieved through the $\mathrm{Na}^{+} \mathrm{K}^{+}$pump. This pump operates constantly maintaining high levels of $\mathrm{K}^{+}$and low levels of $\mathrm{Na}^{+}$requiring ATP for energy. Excess of either cation can cause the pump to either slow down or speed up affecting the amount of energy or ATP needed (Kurts et al. 2013). Balance can also be achieved through intestinal absorption. If $\mathrm{Cl}^{-}$is in excess of $\mathrm{Na}^{+}$it is absorbed and exchanged for $\mathrm{HCO}_{3}{ }^{-}$to achieve neutrality. However, if there is not enough $\mathrm{Na}^{+}$present to allow for absorption of $\mathrm{NaCl}$, excess $\mathrm{HCO}_{3}{ }^{-}$can lead to an acidotic state. Likewise, if $\mathrm{Na}^{+}$is absorbed in excess of $\mathrm{Cl}^{-}$this can lead to metabolic alkalosis. Mobilization of $\mathrm{H}^{+}$in kidney tubules, secretion 
of $\mathrm{H}^{+}$and $\mathrm{NH}_{3}$ production in the kidney all depend on absorption of $\mathrm{Na}^{+}$to neutralize $\mathrm{HCO}_{3}{ }^{-}$. Kidneys conserve $\mathrm{HCO}_{3}{ }^{-}$when experiencing acidosis from extracellular fluids and the reserve is true during alkalosis. Thus, optimal $\mathrm{Cl}^{-}$in relation with other ions is needed to achieve acid-base balance. An additional way this balance is reached is through chloride shift. A a result of tissue metabolism is carbon dioxide production, which reacts with $\mathrm{H}_{2} \mathrm{O}$ to form $\mathrm{H}_{2} \mathrm{CO}_{3}$ inside erythrocytes. Some $\mathrm{H}_{2} \mathrm{CO}_{3}$ is released into plasma and the remainder reacts with $\mathrm{KHbO}_{2}$ to form $\mathrm{HCO}_{3}{ }^{-}$. In plasma, $\mathrm{HCO}_{3}{ }^{-}$is exchanged for $\mathrm{Cl}^{-}$. The imbalance of these ions results in acidosis or alkalosis.

\section{DCAD diets}

Manipulation of DCAD can be used to increase the well-being and productivity of cattle. Research has been done extensively in dairy cows dealing with modification of DCAD. The production diseases of the dairy cow are a manifestation of the cow's inability to cope with the metabolic demands of high production, and they continue to be a cause of economic loss to the dairy industry and an animal welfare concern. Although the term "production diseases" has evolved, traditionally production diseases were considered to be; hypocalcaemia, hypomagnesaemia and ketosis. In recent times, the dairy industry has underwent intensive genetic selection which has increased milk yield to a level where the demand for nutrients from the diet and body tissue reserves often results in ill-health and infertility. According to Payne et al (1973) 'imbalances in the 'input' and 'output' of metabolites required for production or deviations in the normal 'throughput' pathways of the body."

In the context of milk fever prevention, current reviews place strong emphasis on the role of dietary cation anion difference (DCAD). De Garis and Lean (2008) present data from a metaanalysis, which indicate that the effect of DCAD on milk fever incidence is a linear one. This 
implies that reducing DCAD will decrease the risk of milk fever even if the accepted specific thresholds for milk fever prevention after dietary acidification have not been met. Goff (2008) suggests that in field situations diets may be initially formulated to contain $0.5 \%$ less chloride (Cl) than potassium $(\mathrm{K})$ in order to achieve a suitable DCAD, with further modification possibly necessary to bring dietary $\mathrm{Cl}$ to within $0.4 \%$ or $0.3 \%$ of dietary $\mathrm{K}$ (Doherty et al., 2008). Moore et al (2000) found that supplementing the diets of cows with anionic salts in the last 3 weeks before calving at a rate sufficient to decrease DCAD to $-15 \mathrm{meq} / 100 \mathrm{~g}$ of dietary DM and urine $\mathrm{pH}$ to 6.0 prevented most cases of parturient hypocalcemia. Therefore, from the literature we can concluded that modification of DCAD diets can improve the health status of the cow ultimately improving productivity.

Likewise, a study was conducted on Holstein cows during early lactation where cows were offered rations with dietary cation-anion differences. These cows were fed 20, 35 or 50 $\mathrm{mEq}$ from day 0 (calving) until day 42 postpartum. DMI of the respective groups was 3.30, 3.38 and $2.96 \mathrm{~kg} / 100$ of body weight (BW) and milk yield was $25.5,24.2$ and $22.4 \mathrm{~kg} / \mathrm{d}$. It was determined that a DCAD between 23 and $33 \mathrm{mEq} / 100 \mathrm{~g}$ of DM was adequate, whereas 50 mEq/100g DM may be excessive and unpalatable causing a decrease in DMI (Chan et al., 2005). In a meta-analysis looking at 12 studies that included 17 trials and 69 dietary treatments involving 230 dairy cows results showed DCAD affected the performance of lactating cows. Maximum milk yield and DMI was reached when DCAD was 34 and $40 \mathrm{mEq} / 100 \mathrm{~g}$ of dry matter. Blood pH also increased with a DCAD of 34 and $40 \mathrm{mEq} / 100 \mathrm{~g}$, indicating an improved acid-base balance with lactating dairy cows (Hu et al., 2004).

Block (1984) found that decreasing DCAD could lead to positive influence on Ca metabolism and a decrease in milk fever. However, meta-analysis has also shown that the 
decrease of DCAD can also lead to a decrease in DMI. Similarly, Rezac et al. (2014) investigated different DCAD of prepartum diets for the effect on DMI, total serum Ca and performance of transition dairy cows as compared to control diet. Treatments included control DCAD +17.7 meq/100g DM, Bio-Chlor DCAD +2.5 meq/100g DM and SoyChlor DCAD +0.4 meq/100g DM. Serum Ca concentrations did not differ between treatments. DMI intake did decrease in the SoyChlor treatment, however there no negative effects on performance or health of cows. This suggests that DCAD values near zero were insufficient or insignificant on postpartum health and/or performance.

The effect of altering DCAD diets has also been studied in beef cattle. Hersom et. al (2009) looked into the effect of DCAD on cow BW, DMI, and pH of blood and urine. Cows were fed a either a negative (low) DCAD diet ( $-0.9 \mathrm{mEq} / 100 \mathrm{~g}$ of DM) or positive (high) DCAD $\operatorname{diet}(+25.0 \mathrm{mEq} / 100 \mathrm{~g}$ of DM $)$. Treatment had no effect on cow ADG $(P=0.71)$. There was no difference in DMI prior to day 28 of the study, but was greater for cows with a positive DCAD diet after day $28(P<0.001)$. Blood gas and $\mathrm{pH}$ measures peaked on $\mathrm{d} 21$ for high-DCAD and declined from d 0 to 42 in low-DCAD cows. Thus, altering DCAD can have effect on cow acidbase physiology. Additionally, Schnoonmaker and colleagues (2013) also found that DCAD can have an effect on the gain of Simmental x Angus crossbred steers. Gain and gain:feed responded quadratically to $\operatorname{DCAD}(P<0.01)$, increasing from -16 to $0 \mathrm{DCAD}$ and decreasing from +16 to 0 DCAD. Thus, we can conclude that altering DCAD diets can both improve health status and productivity and raises the question of the role of the renal system in compensating for changes in DCAD and ultimately how the body maintains plasma osmolarity. 


\section{Plasma}

\section{Osmolarity}

There are two main fluid compartments water occupies in the body. About two-thirds is contained in intracellular fluid compartment (ICF), which is the fluid within the cells of the body. The remaining one-third is the water outside the cells known as the extracellular fluid compartment (ECF). The ECF is divisible into two compartments. Plasma, which is the fluid part of blood and interstitial fluid, the fluid in the spaces between tissue cells.

The body's fluids are composed of electrolytes and nonelectrolytes. Non-electrolytes have bonds that prevent them from disassociating in a solution and no electrically charged compounds are formed. In contrast, electrolytes are chemical compounds that dissociate into ions in water. When these minerals are dissolved in water, they dissolve into their ionic states. Positively charged ions, such as sodium and potassium are classified as cations, whereas negative ions such as chloride and sulfur are considered anions. Since these ions are charged particles, they can conduct an electrical current. Electrolytes have much greater osmotic power than nonelectrolytes because each electrolyte molecule disassociates into at least two ions.

Many factors can change ECF and ICF volumes because water moves freely between compartments, however, the osmolarities of all body fluids are equal. With that being said, substances must pass through both plasma and interstitial fluid to reach intracellular fluid. In the kidneys, exchanges occur between plasma and the "outside world". These changes alter plasma composition and volume. Increasing the ECF solute content (mainly sodium chloride) causes osmotic and volume changes in the ICF - generally, a shift of water out of cells. Conversely, decreasing ECF osmolarity causes water to move into the cells. Thus, ECF solute concentration determines ICF volume (Shaw, 2005). 


\section{Techniques}

There are many different techniques used to measure osmolarity including osmotic pressure, freezing point depression, boiling point elevation and vapor pressure depression. Osmotic pressure is the minimum pressure needed to be applied to a solution to prevent the inward flow of water across a semipermeable membrane. However, osmotic pressure is rarely measured because of the difficulty obtaining a true or "perfect" semipermeable membrane. Early efforts to measure osmotic pressure used animal membranes (e.g. bladder) that were leaky to some solutes and therefore were not true semipermeable membranes. Today better artificial membranes are available although the techniques involved are difficult and laborious. Thus, osmotic pressure is not the method of choice for determining osmolarity of biological solutions and is rarely used.

Freezing point depression measures the reduction in a solvent's chemical potential that results in the addition of solute also causing a reduction in the solution's freezing point. Because of this relationship between freezing point and chemical potential, this method is frequently used. It has the advantages of being quick and easy to measure on sample volumes as small as 20 $u l$. However, the thermodynamic equation that links freezing point depression and osmolarity incorporates several critical assumptions. It assumes the solution is very dilute and that it demonstrates ideal behavior. However, biological solutions are rarely ideal and the potential problems from non-ideal solutions are generally overlooked.

Although boiling point is one of the colligative properties, this method has many shortcomings. As with freezing point depression, boiling point errors result from the variation of thermodynamic assumptions made in the computation of osmolarity. Furthermore, the method is 
inappropriate for solutions containing substances that are unstable at high temperatures.

Consequently, boiling point elevation is rarely used as method.

Vapor pressure corresponds to Raoult's law which states that that the partial vapor pressure of each component of an ideal mixture of liquids is equal to the vapor pressure of the pure component multiplied by its mole fraction in the mixture (Guggenheim, 1937). Above the surface of a solution, molecules of solvent are present in the gaseous phase. Sealing the solution in a vessel will bring the liquid and vapor pressure to some stable value. Under these conditions, the chemical potential of solution's solvent can be determined by comparing its vapor pressure to that of the pure solvent. An advantage of vapor pressure osmometry is that the solution can be measured without undergoing a change in state. Furthermore, vapor pressure osmometry can be performed throughout a wide temperature range, as long as the instrument is stabilized at a constant temperature and is properly calibrated. Thus, vapor pressure osmometry is commonly used to measure osmolarity (Sweeny and Beuchat, 1993).

\section{ADH}

It is known that antidiuretic hormone (ADH) is a hormone made by the hypothalamus in the brain and stored in the posterior pituitary gland. ADH tells the kidneys how much water to conserve, yet the secretion of ADH is regulated mainly by osmolarity of plasma (Engelking, 2002). Osmotic sensors in the hypothalamus react to the concentration of particles in your blood. These particles include molecules of sodium, potassium, chloride, and carbon dioxide. When particle concentration is not balanced, or blood pressure is too low, these sensors and baroreceptors tell your kidneys to store or release water to maintain a healthy range of these substances. This demonstrates that renal function and plasma osmolarity are linked. 
The normal range for osmolarity of "healthy" cattle varies among source. Constable (1970) reported 290-336 mOsm as the range for osmolarity of healthy cattle, while Rousel et al (2014) and Cockcroft and Jackson (2002) reported similar ranges, 270-310 mOsm and 270-306 mOsm, respectively. Although, these ranges differ from one another, it can be concluded from the above that osmolarity values may fluctuate. This fluctuation may be due to several factors. There is an osmotic gap that is the difference between the difference in the actual osmolarity and the calculated osmolarity. However, this gap is normal less than 10-15 mOsm/kg or L. When the gap is increased it indicates the presence of other osmotically active solutes which are not taken into account in the calculation of osmolarity. As cell membranes in general are freely permeable to water, the osmolality of the extracellular fluid (ECF) is approximately equal to that of the intracellular fluid (ICF). Therefore, plasma osmolarity is a guide to intracellular osmolarity. Therefore, using the above knowledge and knowing that renal function plays a major role in metabolism, the largest factor of efficiency, plasma osmolarity may be used as a way to identity efficiency in beef cattle. Knowledge of the relationship between plasma osmolarity and RFI may lead to future advancements in feed efficiency, reducing the amount of time needed to calculate RFI and ultimately improving profitability. 


\section{Section 2: Materials and Methods}

\section{Samples}

Previously extracted samples by Shaffer et al. (2011) investigating the relationship between heifer fertility and RFI over a two year period (2008 and 2009) was used. Plasma samples $(n=67 ; n=70)$ collected weekly for progesterone analysis in that study were subsequently used. Upon original collection time to current, $(1 \mathrm{~mL})$ plasma samples were stored at $-60^{\circ} \mathrm{C}$ and thawed at room temperature. Ten different time points were selected from each year of the study (2008 and 2009). These time points occurred weekly starting on day 14 until day 77 of an 84 day test collecting feed intake and growth data for RFI determination.

\section{Determination of osmolarity}

Osmolarity was determined using the Vapro® Vapor Pressure Osmometer Model 5520.

The machine was adjusted to room temperature before all readings. Adjustment could be determined using the "Temperature Drift" scale which displayed when internal temperature had stabilized. The machine was calibrated using three standards (100, 290 and $1000 \mathrm{mOsm})$. Calibration was conducted before readings of each sample set. Upon thawing and acclimation to room temperature, $10 \mu 1$ of plasma was aspirated into a micropipettor tip. The sample was then pipetted onto a solute-free paper disc located on the sample holder. The disc was then inserted into the machine. Dew point temperature depression is measured with a resolution of 0.00031 ${ }^{\circ} \mathrm{C}$. The microprocessor-controlled measurement cycle requires 80 seconds. Three readings per sample was conducted allowing an average reading to be determined for each.

\section{Trait Relationships}

Relationships between osmolarity and various production traits previously recorded by Shaffer et. al (2011) were investigated. These traits include feed intake, metabolic body size (MBS), average daily gain (ADG) and residual feed intake (RFI). As well as carcass traits 
measured in year 1 heifers such as; ribeye area (REA), intramuscular fat (IMF), rib fat and rump fat.

\section{Statistical analysis}

All data were analyzed using the CORR procedures of SAS. Significance was accepted at $P<0.05$. 


\section{Section 3: Results}

\section{Osmolarity over time}

Osmolarity was determined for ten different time points and nine time points for year 1 and 2, respectively. The average osmolarity values for 2008 ranged from $277.99 \mathrm{mOsm}$ to $310.53 \mathrm{mOsm}$. Average values across time started high on day 14 (308.08 mOsm) and ended high on day 77 (310.53 mOsm) with considered variation throughout the test (Figure 1). Average osmolarity for 2009 was numerically higher than 2008 , ranging from $288.34 \mathrm{mOsm}$ to 336.04mOsm (Figure 2). Like 2008 samples, 2009 samples showed constant variation in osmolarity within the test.

\section{Determination of relationships between osmolarity and carcass traits}

Ultrasound carcass measurements taken one week post trial (2008; day 84) showed no significant correlations with osmolarity. Rib fat had no correlations to osmolarity ( $P \geq 0.98)$. Additionally, no significant correlations existed between rump fat and osmolarity $(P \geq 0.90)$. Positive correlations between rump fat and osmolarity occur on all time points, except days 28 and 49. Correlations between osmolarity and REA occurred on days 21 and $35(P=0.04$ and $P \geq 0.0002$, respectively). No correlations existed between IMF and osmolarity $(P \geq 0.13)$ [Table 1].

\section{Determination of relationships between osmolarity and production traits 2008}

There were no significant correlations between osmolarity and MBS on days 14, 21, 28, 42, 49, 63, 70, 77( $P \geq 0.88)$ [Table 2]. However, there was a tendency on days 35 and 56 ( $P \geq$ $0.06 ; P \geq 0.07)$. Additionally, there were no significant correlations between osmolarity and ADG $(P \geq 0.99)$. No significant correlations existed between osmolarity and average intake on days $14,21,28,35,42,49,56,63$, and $77(P \geq 0.90)$. A weak association occurred on day 70 between average intake and osmolarity $(P=0.08)$. There was a tendency for relationships 
between RFI and osmolarity on days 63 and 70 ( $P=0.09$ and $P=0.02$, respectively). No relationships were significant at other time points. Table 2 displays all $r$ values for MBS, ADG, average intake and RFI.

When classified by low (LOW), medium (MED) and high (HIGH) RFI there was a relationship between LOW-RFI and osmolarity on day $70(P=0.03)$. Additionally there was a relationship between LOW-RFI and osmolarity on day $63(P=0.009)$. No further relationships existed (Table 4).

2009

There were no significant relationships between osmolarity and MBS. Additionally, there were no significant relationships between osmolarity and ADG. There were no relationships between osmolarity and average intake on days $14,21,35,42,49,63,70,77(P \geq 0.98)$ [Table 3]. There was a relationship between osmolarity and average intake on day $56(P=0.01)$ [Table 3]. Furthermore, no relationships occurred between osmolarity and RFI on days 14, 21, 35, 42, $49,63,70,77$. However, a relationship between osmolarity and RFI did occur on day 56 ( $P$ $=0.05)$ [Table 3].

When classified by low (LOW), medium (MED) and high (HIGH) RFI there was a relationship between LOW-RFI and osmolarity on day $63(P=0.04)$. Additionally, there were relationships between HIGH-RFI and osmolarity on days $21(P=0.07)$ and day $35(P=0.003)$. No further relationships existed (Table 5). 


\section{Section 4: Discussion}

These results indicate that there are no direct relationships between osmolarity determined from blood samples and RFI. Thus, in this investigated study osmolarity cannot be used as a method to predict feed efficiency. It was noted that a weak association between RFI and osmolarity did occur on day 70 , however, this is not surprising as both osmolarity and average intake had a trending relationship for that same time point. It is important to note, that when separate by low (LOW), medium (MED) and high (HIGH) relationships did exist. This may suggest that although osmolarity and RFI aren't directly linked, osmolarity may be able to predict if an animal will have a high or low RFI value. However, this classification of low, medium and high is strictly based off of these groups of heifers and may differ with other groups depending on the range of RFI. Additionally, there were no significant correlations between osmolarity and MED-RFI where the majority of the population falls. Although, there are no significant relationships between blood osmolarity and RFI, osmolarity values fluctuated over weekly time points. Osmolarity will fluctuate based on the body's water balance. Water was available ad libtum, thus heifers could drink during any point of the day. This means that because water intake was not monitored, heifers were possibly self-balancing cation-anion difference in their body. Monitoring the intake of water may be able to explain the fluctuation in osmolarity values for it is not known the amount of water consumed or if heifers were drinking prior to blood sampling or not. Additionally, samples were taken weekly throughout the study. It may be beneficial to sample animals prior to adjustment to diet and environment to determine if any differences occur prior to standardization. Also, sampling more frequently may display a more accurate representation of osmolarity values.

We know that sodium plays the largest role in cation-anion balance thus analyzing for sodium levels may be a better model for determining efficiency in the body. As sodium levels 
may be a more direct relationship and indicator of cation-anion balance. Another possible avenue to determining efficiency would be to analyze cortisol and ADH levels in the body. The heifers that served as models in this study were all housed in a standardized environment, however, we do not know how each animal individually handled stress. Cortisol levels are an indicator of stress on the animal. Richardson et al. (2004) reported a trend between RFI and cortisol, as low efficiency steers had higher cortisol levels. However, the steers used in the Richardson et al. (2004) study were all sampled at a certain physiological state, thus limiting the inferences on biological patterns as the cattle develop physiologically. Caroll et al. (2014) reported an interaction between corticotropin-releasing hormone $(\mathrm{CRH})$, stress releasing hormone and vasopressin (VP) or ADH. We know that $\mathrm{ADH}$ regulates the amount of water the kidneys conserved which contributes to cation-anion balance in the body. Thus, these two hormones may be indicator of stress on the animal and how efficiently the animal is responding. However, levels need to be studied frequently over the duration of the trial. While blood osmolarity alone may not be a direct source for determining feed efficiency, analysis of biological markers and relationships within the body may be a possible method for determining efficiency in beef cattle. 


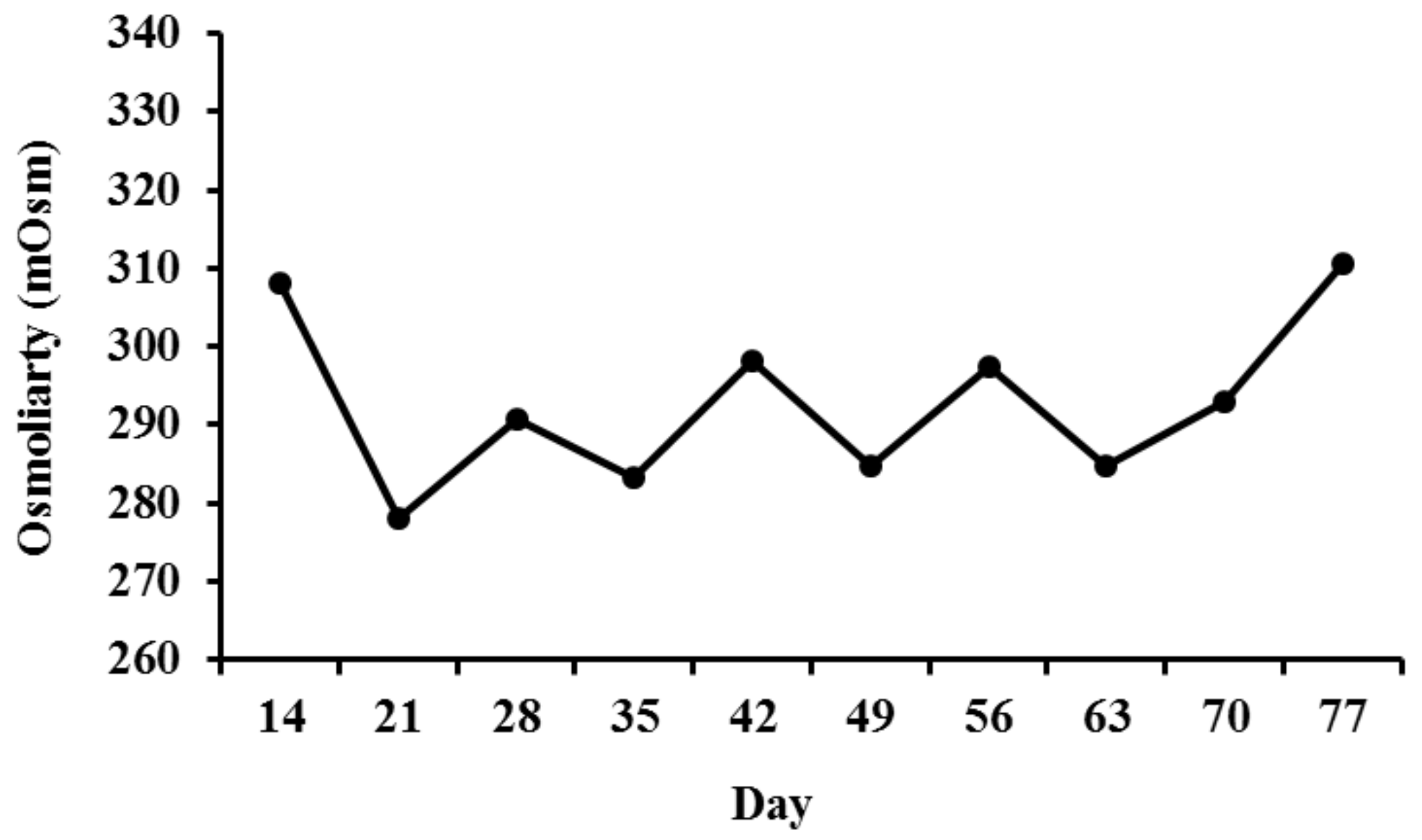

Figure 1: Average osmolarity of 2008

Average $(n=67)$ plasma osmolarity taken weekly over a 77 day trial in 2008 . 


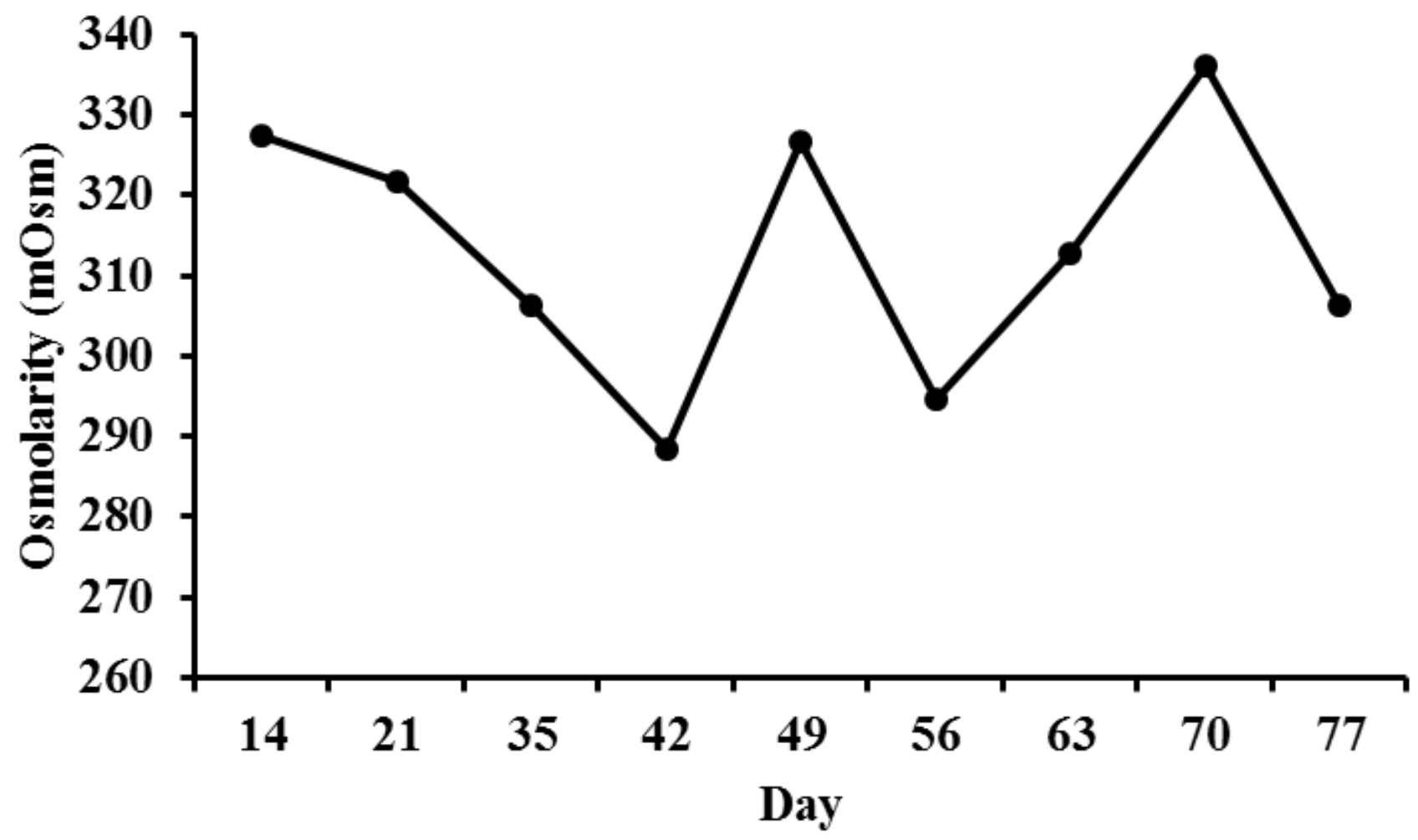

Figure 2: Average osmolarity 2009

Average $(n=70)$ plasma osmolarity taken weekly over a 77 day trial in 2009. 
Table 1: Pearson correlations between osmolarity and carcass traits 2008

\begin{tabular}{lcccccccccc}
\hline \hline & \multicolumn{10}{c}{ Day } \\
\cline { 2 - 11 } & $\mathbf{1 4}$ & $\mathbf{2 1}$ & $\mathbf{2 8}$ & $\mathbf{3 5}$ & $\mathbf{4 2}$ & $\mathbf{4 9}$ & $\mathbf{5 6}$ & $\mathbf{6 3}$ & $\mathbf{7 0}$ & $\mathbf{7 7}$ \\
\hline Rib fat & 0.104 & 0.137 & 0.003 & 0.133 & 0.167 & -0.119 & 0.015 & -0.002 & 0.002 & 0.124 \\
$P$-value & 0.42 & 0.30 & 0.97 & 0.13 & 0.20 & 0.34 & 0.90 & 0.98 & 0.98 & 0.32 \\
Rump fat & 0.041 & 0.110 & -0.052 & 0.220 & 0.163 & -0.194 & 0.014 & 0.086 & 0.057 & 0.022 \\
$P$-value & 0.75 & 0.41 & 0.67 & 0.09 & 0.21 & 0.11 & 0.90 & 0.48 & 0.64 & 0.86 \\
& & & & & & & & & & \\
IMF & 0.055 & 0.198 & 0.001 & 0.118 & -0.002 & -0.080 & -0.104 & 0.022 & 0.022 & -0.081 \\
$P$-value & 0.67 & 0.13 & 0.99 & 0.37 & 0.98 & 0.52 & 0.40 & 0.85 & 0.53 & 0.51 \\
& & & & & & & & & & \\
REA & 0.024 & 0.262 & 0.078 & 0.469 & 0.074 & 0.077 & -0.075 & -0.005 & 0.019 & 0.060 \\
$P$-value & 0.85 & 0.04 & 0.53 & 0.0002 & 0.57 & 0.53 & 0.54 & 0.96 & 0.87 & 0.63
\end{tabular}


Table 2: Pearson correlations between osmolarity and production traits 2008

\begin{tabular}{lcccccccccc}
\hline \hline & \multicolumn{10}{c}{ Day } \\
\cline { 2 - 12 } & $\mathbf{1 4}$ & $\mathbf{2 1}$ & $\mathbf{2 8}$ & $\mathbf{3 5}$ & $\mathbf{4 2}$ & $\mathbf{4 9}$ & $\mathbf{5 6}$ & $\mathbf{6 3}$ & $\mathbf{7 0}$ & $\mathbf{7 7}$ \\
\hline MBS & 0.089 & 0.110 & 0.018 & 0.242 & 0.112 & -0.086 & -0.223 & -0.125 & 0.058 & 0.025 \\
$P$ - value & 0.49 & 0.41 & 0.88 & 0.06 & 0.39 & 0.49 & 0.07 & 0.31 & 0.63 & 0.84 \\
ADG & 0.007 & -0.223 & -0.092 & -0.041 & -0.102 & -0.101 & -0.078 & -0.002 & -0.000 & 0.020 \\
$P$ - value & 0.95 & 0.09 & 0.45 & 0.75 & 0.43 & 0.41 & 0.53 & 0.98 & 0.99 & 0.87 \\
AVG & -0.051 & -0.037 & 0.059 & 0.120 & 0.046 & -0.183 & 0.143 & 0.124 & 0.211 & -0.018 \\
INTAKE & 0.69 & 0.78 & 0.63 & 0.36 & 0.72 & 0.14 & 0.90 & 0.31 & 0.08 & 0.88 \\
$P$ - value & & & & & & & & & & \\
RFI & -0.100 & 0.091 & 0.143 & 0.123 & 0.105 & -0.145 & 0.150 & 0.206 & 0.266 & -0.046 \\
$P$ - value & 0.44 & 0.50 & 0.24 & 0.35 & 0.42 & 0.24 & 0.22 & 0.09 & 0.02 & 0.71
\end{tabular}


Table 3: Pearson correlations between osmolarity and production traits 2009

\begin{tabular}{lccccccccc}
\hline \hline & \multicolumn{10}{c}{ Day } \\
\cline { 2 - 10 } & $\mathbf{1 4}$ & $\mathbf{2 1}$ & $\mathbf{3 5}$ & $\mathbf{4 2}$ & $\mathbf{4 9}$ & $\mathbf{5 6}$ & $\mathbf{6 3}$ & $\mathbf{7 0}$ & $\mathbf{7 7}$ \\
\hline MBS & 0.143 & 0.114 & 0.07 & 0.05 & 0.153 & -0.114 & 0.131 & 0.156 & -0.073 \\
$P$-value & 0.24 & 0.34 & 0.55 & 0.68 & 0.21 & 0.35 & 0.28 & 0.19 & 0.54 \\
ADG & 0.130 & -0.002 & -0.053 & --0.009 & 0.127 & -0.197 & 0.142 & 0.258 & -0.110 \\
$P$-value & 0.28 & 0.98 & 0.66 & 0.30 & 0.30 & 0.10 & 0.24 & 0.24 & 0.36 \\
AVG & -0.011 & -0.053 & 0.001 & -0.082 & 0.135 & -0.286 & -0.066 & 0.010 & -0.106 \\
INTAKE & 0.92 & 0.66 & 0.98 & 0.50 & 0.27 & 0.01 & 0.58 & 0.93 & 0.37 \\
$P$-value & & & & & & & & & \\
RFI & -0.061 & -0.063 & 0.010 & -0.087 & 0.095 & -0.234 & -0.119 & -0.008 & -0.073 \\
$P$ - value & 0.61 & 0.59 & 0.92 & 0.47 & 0.44 & 0.05 & 0.32 & 0.94 & 0.54
\end{tabular}


Table 4: Pearson correlations between osmolarity and RFI by group 2008

\begin{tabular}{lccccccccccc}
\hline \hline & \multicolumn{10}{c}{ Day } \\
\cline { 2 - 12 } & $\mathbf{1 4}$ & $\mathbf{2 1}$ & $\mathbf{2 8}$ & $\mathbf{3 5}$ & $\mathbf{4 2}$ & $\mathbf{4 9}$ & $\mathbf{5 6}$ & $\mathbf{6 3}$ & $\mathbf{7 0}$ & $\mathbf{7 7}$ \\
\hline RFI (LOW) & -0.276 & -0.249 & 0.049 & 0.052 & 0.087 & 0.176 & 0.167 & 0.039 & 0.454 & 0.003 \\
$P$-value & 0.22 & 0.28 & 0.82 & 0.85 & 0.70 & 0.43 & 0.46 & 0.86 & 0.03 & 0.98 \\
RFI (MED) & -0.256 & 0.127 & 0.177 & 0.169 & 0.168 & -0.251 & -0.240 & 0.151 & -0.126 & -0.097 \\
$P$-value & 0.26 & 0.59 & 0.41 & 0.46 & 0.50 & 0.25 & 0.26 & 0.49 & 0.56 & 0.66 \\
RFI (HIGH) & 0.389 & 0.396 & -0.032 & 0.306 & 0.370 & 0.008 & 0.064 & 0.542 & 0.041 & 0.050 \\
$P$-value & 0.11 & 0.11 & 0.88 & 0.16 & 0.10 & 0.96 & 0.77 & 0.009 & 0.85 & 0.82
\end{tabular}


Table 5: Pearson correlations between osmolarity and RFI by group 2009

\begin{tabular}{lccccccccc}
\hline \hline & \multicolumn{10}{c}{ Day } \\
\cline { 2 - 10 } & $\mathbf{1 4}$ & $\mathbf{2 1}$ & $\mathbf{2 8}$ & $\mathbf{3 5}$ & $\mathbf{4 2}$ & $\mathbf{4 9}$ & $\mathbf{5 6}$ & $\mathbf{6 3}$ & $\mathbf{7 7}$ \\
\hline RFI (LOW) & 0.014 & 0.294 & -0.093 & -0.073 & 0.083 & 0.332 & 0.017 & -0.421 & 0.187 \\
$P$ - value & 0.95 & 0.17 & 0.56 & 0.73 & 0.73 & 0.12 & 0.93 & 0.04 & 0.39 \\
RFI (MED) & -0.009 & -0.104 & 0.276 & -0.349 & -0.085 & 0.032 & -0.125 & -0.060 & 0.191 \\
$P$ - value & 0.96 & 0.63 & 0.21 & 0.12 & 0.69 & 0.88 & 0.56 & 0.67 & 0.38 \\
RFI (HIGH) & 0.006 & -0.370 & -0.167 & -0.572 & -0.132 & -0.110 & -0.110 & 0.070 & 0.054 \\
$P$ - value & 0.97 & 0.07 & 0.46 & 0.003 & 0.53 & 0.60 & 0.60 & 0.74 & 0.79
\end{tabular}




\section{Literature Cited}

Ames, D. R., and D. R. Brink. 1977. Effect of Temperature on Lamb Performance and Protein Efficiency Ratio. J. Anim. Sci. 44:136-144.

Archer, J. A., P. F. Arthur, R. M. Herd, P. f Parnell, and W. S. Pitchford. 1997. Optimum Postweaning Test for Measurement of Growth Rate, Feed Intake and Feed Efficiency in British Breed Cattle. J. Anim. Sci . 75:2024-2032.

Arthur, P. F., J. A. Archer, D. J. Johnston, R. M. Herd, E. C. Richardson, and P. F. Parnell. 2001. Genetic and phenotypic variance and covariance components for feed intake, feed efficiency and other postweaning traits in Angus cattle. ASAS. 79:2805-2811.

Arthur, P.F., G. Renand, D. Krauss. 2001b. Genetic and phenotypic relationships among different measures of growth and feed efficiency in young Charolais bulls. Livest Prod Sci. 68:131-139.

Arthur PF, Herd RM, Wilkins JF, Archer JA (2005) Maternal productivity of Angus cows divergently selected for post-weaning residual feed intake. Aust J. Exp Agr. 45, 985-993.

Arthur, J. P.F., and R.M. Herd. "Residual Feed Intake in Beef Cattle." R. Bras. Zootec. Revista Brasileira De Zootecnia 37.Spe (2008): 269-79.

Bell, A. W. (1995). Regulation of organic nutrient metabolism during transition from late pregnancy to early lactation. J. Anim. Sci. 73(9), 2804.

Blair, E., J. M. Bormann, D. Moser, and T. Marston. 2013. Relationship between residual feed intake and female reproductive measurements in heifers sired by high-or low-residual feed intake Angus bulls1. PAS. 29:46-50.

Block, E. 1984. Manipulating Dietary Anions and Cations for Prepartum Dairy Cows to Reduce Incidence of Milk Fever. J Dairy Sci. 67:2939-2948.

Block, E. 1993. Manipulation of Dietary Cation-Anion Difference of Nutritionally Related Production Diseases, Productivity and Metabolic Responses of Dairy Cows. J Dairy Sci. 77:1437-1450.

Brelin, B., and E. Brannang. 1982. Phenotypic and genetic variation in feed efficiency of growing cattle and their relationship with growth rate, carcass traits and metabolic efficiency. Swed. J. Agr Res. 12:29-34.

Brody, S. 1945. Bioenergetics and growth, with special reference to the efficiency complex in domestic animals. Reinhold Publishing Corp., New York. 
Chan, P., J. West, J. Bernard, and J. Fernandez. 2005. Effects of Dietary Cation-Anion Difference on Intake, Milk Yield, and Blood Components of the Early Lactation Cow. J Dairy Sci. 88:4384-4392.

Crampton, E. W. \& Harris, L. E. (1969). Applied Animal Nutrition, 2nd ed., p. 64. San Francisco: Freeman \& Co

Crews Jr, D. H. "Genetics of Efficient Feed Utilization and National Cattle Evaluation: A Review." Genetics and Molecular Research (2005): 152-65.

Dann, H., Morin, D., Bollero, G., Murphy, M., \& Drackley, J. (2005). Prepartum Intake, Postpartum Induction of Ketosis, and Periparturient Disorders Affect the Metabolic Status of Dairy Cows. J Dairy Sci. 88(9), 3249-3264.

Degaris, P. J., \& Lean, I. J. (2008). Milk fever in dairy cows: A review of pathophysiology and control principles. Vet. J. 176(1), 58-69.

Desvergne, B., Michalik, L., Wahli, W. 2006. Transcriptional regulation of metabolism. Physiol. Rev.86:465-514

Doherty, M., \& Mulligan, F. (2008). Production diseases of the transition cow. Amsterdam: Elsevier.

Eaton, D., and J. Pooler. 2013. The McGraw-Hill Companies, Inc. 8th ed. The McGraw-Hill Companies, Inc.

Emery, R. S., Liesman, J. S., \& Herdt, T. H. (1992). Metabolism of long-chain fatty acids by ruminant liver. J of Nutr. 122(3), 832-837.

Engelking, L. R. 2002. Review of veterinary physiology. Teton NewMedia, Jackson, WY.

Ferrell, C. F., and T. G. Jenkins. 1985. Cow Type and the Nutritional Environment: Nutritional Aspects. J. Anim. Sci. 61.

Fitzhugh, H. A., and S. C. S. Taylor. 1971. Genetic Analysis of Degree of Maturity. J. Anim. Sci. 33:717.

Fontoura, A. B. P., Y. R. Montanholi, M. D. D. Amorim, R. A. Foster, T. Chenier, and S. P. Miller. 2015. Associations between feed efficiency, sexual maturity and fertility-related measures in young beef bulls. J. Anim. Sci. 10:96-105.

Gregory, K. E. Beef Cattle Type for Maximum Efficiency "Putting It All Together". J. Anim. Sci 34. 
Gunsett, F. C. "Problems associated with selection for traits defined as a ratio of two component traits." Proceedings of the 3rd World Congress of Genetics Applied to Livestock

Production. Vol. 11. 1986.

Guggenheim, E.A. 1937. The theoretical basis of Raoult's law. Trans. Faraday Soc. 33:151-156.

Hafla, A. N., P. A. Lancaster, G. E. Carstens, D. W. Forrest, J. T. Fox, T. D. A. Forbes, M. E. Davis, R. D. Randel, and J. W. Holloway. 2012. Relationships between feed efficiency, scrotal circumference, and semen quality traits in yearling bulls. J. Anim. Sci 90:39373944.

Harrington, James M., Daniel J. Young, Amal S. Essader, Susan J. Sumner, and Keith E. Levine. "Analysis of Human Serum and Whole Blood for Mineral Content by ICP-MS and ICPOES: Development of a Mineralomics Method." Biological Trace Element Research Biol Trace Elem Res 160.1 (2014): 132-42.

Herd, R.m., and S.c. Bishop. "Genetic Variation in Residual Feed Intake and Its Association with Other Production Traits in British Hereford Cattle." Livest Prod Sci. 63.2 (2000): 111-19.

Herd, R. M., V. H. Oddy, and E. C. Richardson. 2004. Biological basis for variation in residual feed intake in beef cattle 1. Review of potential mechanisms. Aust J. Exp Agr. 44:423-430.

Herd, R. M., and P. F. Arthur. 2009. "Physiological Basis for Residual Feed Intake." J. Anim. Sci. 87.Num 14, Supp 09.

Herd, R. M., J. A. Archer, and P. F. Arthur. 2003. Reducing the cost of beef production through genetic improvement in residual feed intake: Opportunity and challenges to application. J. Anim. Sci. 81:E9-E17.

Herdt, T.H. Ruminant adaptation to negative energy balance. Vet. Clin. North Am. Food Anim. Pract.16:215-230.

Hersom, M. J., G. R. Hansen, and J. D. Arthington. 2009. Effect of dietary cation-anion difference on measures of acid-base physiology and performance in beef cattle. J. Anim. Sci. 88:374-382.

Holtenius, P. Hormonal regulation related to the development of fatty liver and ketosis. 1993. Acta Vet. Scand. Suppl.89:55-60.

Hotovy, S. K., K. A. Johnson, D. E. Johnson, G. E. Carstens, R. M. Bourdon, and G. E. Seidel. 1991. Variation among twin beef cattle in maintenance energy requirements. J. Anim. Sci. 69:940.

Hoque, M. A., and K. Suzuki. "Genetics of Residual Feed Intake in Cattle and Pigs: A Review." Asian Austral J. Anim. 22.5 (2009): 747-55. 
Hu, W., and M. Murphy. 2004. Dietary Cation-Anion Difference Effects on Performance and Acid-Base Status of Lactating Dairy Cows: A Meta-Analysis. J Dairy Sci. 87:2222-2229.

Jackson, P. G. G., and P. D. Cockcroft. 2002. Clinical examination of farm animals. Blackwell Science, Oxford, UK.

Janovick, N., Boisclair, Y., \& Drackley, J. (2011). Prepartum dietary energy intake affects metabolism and health during the periparturient period in primiparous and multiparous Holstein cows1. J Dairy Sci. 94(3), 1385-1400

Jin, H.-B., Gu, Z.-Y., Yu, C.-H., Li, Y.-M. 2005. Association of nonalcoholic fatty liver disease with type 2 diabetes: Clinical features and independent risk factors in diabetic fatty liver patients. Hepatobiliary Pancreat Dis. Int.4:389-392.

Kearney, G. A., B. W. Knee, J. F. Graham, and S. A. Knott. 2004. The length of test required to measure liveweight change when testing for feed efficiency in cattle. Aust J. Exp Agr.. $44: 411$.

Kennedy, B.W., J.H.J. van der Werf and T.H.E Meuwissen. 1993. Genetic and statistical properties of residual feed intake. J. Anim. Sci 71:3229-3250.

Kloosterman, E. W., and C. F. Parker. 1976. Effect of size, breed and sex upon feed efficiency.

Koch, R. M., L. A. Swiger, D. Chambers, and K. E. Gregory. 1963. Efficiency of feed use in beef cattle. J. Anim. Sci. 22:486-494.

Koots. K.R. and J.P Gibson 1998. Economic values for beef production traits from a herd level bioeconomic model. Can J Anim Sci. 78: 29-45.

Korver, S. 1988. Genetic aspects of feed intake and feed efficiency in dairy cattle: a review. Livest Prod Sci. 22:486-494.

Kurts, C., U. Panzer, H.-J. Anders, and A. J. Rees. 2013. The immune system and kidney disease: basic concepts and clinical implications. Nat Immunol.

Lawerence, J. D., Z. Wang, and D. D. Loy. 1999. Elements of Cattle Feeding Profitability in Midwest Feedlots. J Agr Econ.

Leroy, A. M. (1970). Publs EUY. Ass. Anim. Prod. no. 13, p. 25

Lofgreen G P \& Garrett W N. A system for expressing net energy requirements and feed values for growing and finishing beef cattle. J. Anim. Sci. 27:793-806, 1968.

Lutiing, P., E. M. Urff, and M. W. A. Verstegen. 1994. Between-animal variation in biological efficiency as related to residual feed consumption. Neth J Agr Sci. 59-67. 
Marshall, D. A., W.R. Parker and C.A. Dinkel. 2001. Factors Affecting Efficiency to Weaning in Angus, Charolais and Reciprocal Cross Cows. J. Anim. Sci. 43:1176-1187.

Mcgarry, J. D. 2002. Banting Lecture 2001: Dysregulation of Fatty Acid Metabolism in the Etiology of Type 2 Diabetes. Diabetes 51:7-18.

Milo, R., and R. Phillips. 2015. Cell biology by the numbers.

Moe, P. W. and H. F. Tyrrell. 1972. The metabolizable energy requirement of pregnant dairy cows. J. Dairy Sci., 55:480.

Moore, S., Vandehaar, M., Sharma, B., Pilbeam, T., Beede, D., Bucholtz, H., Goff, J. (2000). Effects of Altering Dietary Cation-Anion Difference on Calcium and Energy Metabolism in Peripartum Cows. J Dairy Sci. 83(9), 2095-2104.

Montaño-Bermudez , M., M. K. Nielsen, and G. H. Deutscher. 1989. Energy Requirements for Maintenance of Crossbred Beef Cattle with Different Genetic Potential for Milk. J. Anim. Sci . 2279-2288.

Moustgaard, J. 1971. Nutritive influences on reproduction. Journal of Reproductive Medicine $7: 275-278$.

National Research Council - NRC. Nutrient requirements for beef cattle, 7.ed. Washington, DC. National Academic Press, National Academy of Science, 1996.

NRC. 2000. Nutrient Requirements of Beef Cattle. Updated 7th ed. Natl. Acad. Press, Washington, DC.

Nkrumah, J. D., J. A. Basarab, M. A. Price, E. K. Okine, A. Ammoura, S. Guercio, C. Hansen, C. Li, B. Benkel, B. Murdoch, and S. S. Moore. "Different Measures of Energetic Efficiency and Their Phenotypic Relationships with Growth, Feed Intake, and Ultrasound and Carcass Merit in Hybrid Cattle." J. Anim. Sci. 82.8 (2004): 2451.

Patle, B.R. and V.D. Mudgal. 1977. Utilization of dietary energy for maintenance, milk production and lipgenesis by lactating crossbred cows during midstage of lactation. Brit. J. Nutr. 37:22-33.

Payne, J. M., K.G. Hibbitt, B.F. Sansom. 1973. Production disease in farm animals, The Whitefriars Press Ltd., London and Tonbridge, UK

Pearson, K. 1897. Mathematical contributions to the theory of evolution on a form of spurious correlation who may arise when indices are used in the measurement of organs. Proc. Royal Soc. (London) 60:489. 
Pullen, D. L., Palmquist, D., \& Emery, R. (1989). Effect on Days of Lactation and Methionine Hydroxy Analog on Incorporation of Plasma Fatty Acids into Plasma Triglycerides. J Dairy Sci. 72(1), 49-58. doi:10.3168/jds.s0022-0302(89)79079-2

Ray, D. E., Hale, W.H. and J.A. Marchello. 1969. Influence of Season, Sex and Hormonal Growth Stimulants on Feedlot Performance of Beef Cattle. J. Anim. Sci. 29:490-495.

Reynolds, C., Aikman, P., Lupoli, B., Humphries, D., \& Beever, D. (2003). Splanchnic Metabolism of Dairy Cows During the Transition From Late Gestation Through Early Lactation. J. Dairy. Sci. 86(4), 1201-1217.

Rezac, D. J., E. Block, D. Weber, M. J. Brouk, and B. J. Bradford. 2014. Effects of prepartum dietary cation-anion difference and acidified coproducts on dry matter intake, serum calcium, and performance of dairy cows. J. Anim. Sci. 92:666-675.

Richardson, F. D., J. Oliver, and G. P. Y. Clarke. Analyses of some factors which affect the productivity of beef cows and of their calves. Animal Production 21:41-49.

Richardson, E. C., and R. M. Herd. "Biological Basis for Variation in Residual Feed Intake in Beef Cattle. 2. Synthesis of Results following Divergent Selection." Aust J. Exp Agr. 44.5 (2004): 431. Web.

Robinson, J. B., D. R. Ames, and G. A. Milken. 1986. Heat Production of Cattle Acclimated to Cold, Thermoneutrality and Heat When Exposed to Thermoneutrality and Heat Stress. J. Anim. Sci. 62:1434-1440.

Sainz, R. D., and P. V. Paulino. 2004. Residual Feed Intake. eScholarship-University of California. Available from: http;//eprints.cdlib.org/uc/item/9w93f7ks

Schoonmaker, J. P., K. T. Korn, K. N. Condron, C. N. Shee, M. C. Claeys, T. D. Nennich, and R. P. Lemenager. 2013. Effect of decreasing dietary cation anion difference on feedlot performance, carcass characteristics, and beef tenderness. J. Anim. Sci. 91:5762-5768.

Shaffer, K. S., P. Turk, W. R. Wagner, and E. E. D. Felton. 2011. Residual feed intake, body composition, and fertility in yearling beef heifers12. J. Anim. Sci. 89:1028-1034. doi:10.2527/jas.2010-3322.

Shaw, L. 2005. Anatomy and physiology. Nelson Thornes, Cheltenham.

Simeone, A., and V. Beretta. 2005. A Review on Developments and Research in Livestock Systems. Wageningen Academic Publishers.

Smith, G. W. 2014. Fluid and Electrolyte Therapy, An Issue of Veterinary Clinics of North America: Food Animal Practice. 
Sweeny, T. E. and C.A. Beuchat. 1993. Limitations of methods of osmometry: measuring the osmolality of biological fluids. APS.

Tegtmeier, E. M., and M. D. Duffy. 2011. External Costs of Agricultural Production in the United States. IJAS.1-20.

Vander, A. J. 1995. Renal physiology. McGraw-Hill, Health Professions Division, New York.

Wang, Z., J. D. Nkrumah, C. Li, J. A. Basarab, L. A. Goonewardene, E. K. Okine, D. H. Crews, and S. S. Moore. 2006. Test duration for growth, feed intake, and feed efficiency in beef cattle using the GrowSafe System. J. Anim. Sci. 84:2289.

West, J. 2003. Effects of Heat-Stress on Production in Dairy Cattle. Journal of Dairy Science $86: 2131-2144$. 


\section{ABSTRACT \\ Effects of offering cows medicated mineral containing Altosid® IGR on growth of beef calves}

\section{Taylor Diane Harrison}

Flies can reduce productivity in cattle by way of disease transmission or stress. The objective of this study was to determine the effect of offering beef cows free-choice mineral containing Altosid ${ }^{\circledR}$ IGR on the growth of calves prior to weaning. Cow-calf pairs were randomly assigned to one of three treatments and grazed for $64 \mathrm{~d}$. Treatments included 1). nonmedicated mineral without fly control, 2). non-medicated mineral with fly tags (both cows and calves) and 3). medicated mineral containing Altosid ${ }^{\circledR}$ IGR (2,880 g/ton Chlorteracyline, 90.80 $\mathrm{g} /$ ton, S-Methoprene). Body weights were collected on days 1,28 and 64 and gains reported on days 1 to 28 (period1), 28 to 64 (period2) and overall. Facial fly counts were taken at the beginning (days 2,3), middle (days 31,32) and end of the trial (day 63). Fly traps were utilized to collect representative fly types (flesh, face, house, horn, stable and blow) on days 9, 16, 31, 37, 44, 58 and 64. Mineral intake was similar between treatments (81.65g/d). All data were analyzed using the GLM procedures of SAS. There were no treatment effects on calf ADG period $1(1.13 \mathrm{~kg} / \mathrm{d} ; P=0.93)$, period $2(1.06 \mathrm{~kg} / \mathrm{d}, P=0.28)$ and overall $(1.09 \mathrm{~kg} / \mathrm{d} ; P=0.19)$. There were no treatment effects on cow ADG during period $1(-0.41 \mathrm{~kg} / \mathrm{d} ; P=0.13)$ or period2 ($0.29 \mathrm{~kg} / \mathrm{d} ; P=0.35)$. However, there was a trend $(P=0.08)$ for a treatment effect on cow ADG overall. Cows on treatment 2 lost more BW than the other two treatments. Numerically, cows offered mineral with Altosid $®$ IGR lost the least amount of weight. There were no treatment effects on cow and calf facial fly counts on days $2(P=0.16 ; P=.50), 31(P=0.49 ; P=0.13)$ and $63(P=0.73 ; P=0.27)$, respectively. However, there were treatment effects on cow-facialcounts on day $32(P=<0.01)$ and calf-facial-counts on days $3(P=0.02)$ and $32(P=0.01)$. There were no treatment effects $(P>0.11)$ on fly type found on fly traps. In this study, overall fly load was relatively low throughout the grazing period. Although there were no direct effects of offering cows medicated Altosid ${ }^{\circledR}$ IGR mineral on calf performance, fly induced stress on cows with calves may have been reduced, as they had less weight loss during this study. 


\section{Part II}

\section{Section 1: Literature Review Introduction}

In livestock production systems, parasites are a major cause of economic loss (Corwin, 1997; Willadsen, 2006). External parasites of beef cattle cause substantial financial losses, exceeding \$2 billion annually in the United States (Byford et al., 1992). Production losses associated with fly parasites are directly attributed to blood loss, annoyance, disease exposure, reduced foraging time, and reduced gains (Harvey and Launchbaugh, 1982; Buxton et al., 1985; Boland et al., 2008). Over the last few decades, a number of control strategies have been developed. Historically, the main strategy used to control fly populations is through the use of insecticides. However, over time flies have developed resistance. Consequently, it has become imperative to develop alternative and more effective methods for fly control. Insect growth regulators (IGR) have begun to develop more popularity of use not only for their ease of use, but as IGRs are a more preventative method as opposed to other techniques which focus on control. Thus, the focus of this literature review will be on fly control methods, specifically insect growth regulators, and their influence on calf growth.

\section{Flies}

\section{Life Cycle}

In order, to fully understand the impact of flies on beef cattle production it is imperative to understand first how these flies develop. The six fly species of importance are; blow flies, face flies, house flies, flesh flies, stable flies and horn flies. These fly species have a very simplistic 
life cycle. In general, the female fly lives one to two weeks, consuming blood from the host and leaving the host only to lay eggs in fresh manure. (Blow flies lay eggs in carcass). Eggs hatch in the manure in a matter of one to two days and will continue to grow and feed on the manure for three to five days. The larvae, still in the manure, develop into pupae and emerge in six to eight days. The house fly differs and emerges more rapidly at about two to three days. Once the adult fly emerges out of the manure, it then flies to nearest host animal and the cycle continues.

\section{Blow Fly}

The blow fly, Calliphoridae, is known for its characteristically metallic blue or green appearance. The blow fly is commonly referred to as a blue or green bottle. Female blow flies lay thousands of eggs over their short life span. Egg masses may consist of 40 to over 1,000 eggs, but the larger masses are usually the result of oviposition by several females at the same location. Incubation may last 4 to 4.5 days but hatching usually occurs in less than 24 hours when conditions are warm and humid (Veterinary Entomology, 2015). Maggots usually complete development in 4 to 10 days. At the end of this period, larvae typically burrow in the upper centimeters of the soil and pupate for up to a week. (Walker, 1851). Adult flies emerge from puparia and make their way to the soil surface. About 1 week later, females begin to deposit eggs and the life cycle is repeated. Blow flies usually develop from egg to adult in only 10 to 25 days and complete 4 to 8 generations each year. Calliphoridae females typically mate when the ovaries are mature and will only accept a male once. On the other hand, males will mate repeatedly (Norris, 1965). Blow flies are typically not known to be one of the main nuisances to cattle; however they can prove to be problematic. Blow flies will not only lay their eggs in decaying carcasses, but will also infest wounds resulting from dehorning or castration. 


\section{House Fly}

The house fly, Musca domestica is a well-known pest of both the farm and home. Not only is this fly a nuisance, it can also transport disease-causing organisms. The house fly has a complete metamorphosis with distinct egg, larval or maggot, pupal and adult stages. The house fly overwinters in either the larval or pupal stage under manure piles or in other protected locations. Warm summer conditions are generally optimum for the development of the house fly, and it can complete its life cycle in as little as seven to ten days. However, under suboptimal conditions the life cycle may require up to two months. As many as 10 to 12 generations may occur annually in temperate regions while more than 20 generations may occur in subtropical and tropical regions (Veterinary Entomology, 2015).

Each female fly can lay up to 500 eggs in several batches of 75 to 150 eggs over a three to four day period. Nutrient-rich substrates such as animal manure provide an excellent developmental substrate. Very little manure is needed for larval development, and sand or soil containing small amounts of degraded manure allows for successful belowground development. When the maggot is full-grown, it can crawl up to 50 feet to a dry, cool place near breeding material and transform to the pupal stage (Veterinary Entomology, 2015).

The house fly is 6 to $7 \mathrm{~mm}$ long, with the female usually larger than the male. The female and can be distinguished from the male by the relatively wide space between the eyes (in males, the eyes almost touch). The head of the adult fly has reddish-eyes and sponging mouthparts. The thorax bears four narrow black stripes and there is a sharp upward bend in the fourth longitudinal wing vein. The abdomen is gray or yellowish with dark midline and irregular dark markings on the sides. The underside of the male is yellowish.

The most significant damage related to this fly is annoyance. Adults feed on available blood, sweat, tears and other bodily fluids of the animals. Animals respond to house flies by ear 
flapping, head shaking and pen avoidance. House flies cause little to no harm to livestock, even in large numbers. They are a nuisance and aggravating to livestock but generally do not have ill effects (Williams, 1985).

\section{Face Fly}

The face fly, Musca autumalis is a robust fly that resembles the house fly. It is a nonbiting fly that feeds on animal secretions, nectar and dung liquids. Adult female flies typically cluster around the animal's eyes, mouth and muzzle causing extreme annoyance. Their activity around the animal's eyes allows face flies to serve as vectors of eye diseases and parasites such as pinkeye and eye worms. They are also facultative blood feeders, meaning that they gather around wounds caused by mechanical damage or biting flies.

Male face flies only feed on nectar and dung and spend the majority of their life resting on branches and fences waiting to copulate with females. Females lay their eggs on very fresh manure in pastures and development from egg to adult is usually completed in two to three weeks depending on temperature. Face flies are strong flies that can travel several miles. They are present throughout summer, but populations usually peak in late July and August. Face flies are numerous along waterways, areas with abundant rainfall, areas with trees and shaded vegetation as well on irrigated pastures. Unlike house flies, face flies do not enter darkened barns during summer months. However, upon cooler weather in the fall and winter will enter buildings and enter a state of hibernation. Face flies, like horn flies breed exclusively in fresh cattle manure in pasture. Thus, management strategies around barns that are highly effective against house and stable flies are ineffective (Veterinary Entomology, 2015, Cilek and Knapp, 1994).

\section{Flesh Fly}

The flesh fly, Sarcophagidae looks like the house fly but are general larger. A mature flesh fly ranges from 10 to $20 \mathrm{~mm}$ in length. They are gray with a checkerboard pattern on the 
top of their abdomen and three black stripes running along the top surface of their thorax (house flies have four). They also sometimes have a reddish-brown tip at the end of their abdomen. While the life cycle of flesh flies varies by species and location, generally flies overwinter in their pupal stage within temperate climates and emerge as adults in the spring. Soon after becoming adults, they mate and the female flesh fly may lay eggs. More likely she will deposit from 20-40 larvae that have hatched within her body which she directly lays on the carrion, feces or rotting plant materials. Flesh fly larvae feed for 3 or 4 days and become pupae that burrow into nearby soil and emerge as adults after about 10 to 15 days.

Flesh flies go through several generations each year. Flesh flies are sometimes among the first insects to arrive at a dead animal carcass and are similar to blow flies in biology and habits. Flesh flies are rarely problems as disease carriers and pose little threat to human or livestock health. However, flesh fly larvae have been known to burrow into wounds in the healthy flesh of livestock (Cilek and Knapp, 1994). .

\section{Stable Fly}

Adult stable flies, Stomoxys calcitrans is a filth fly of worldwide medical and veterinary importance. Stable flies are obligate blood feeders and primarily attack cattle and horses for a blood meal. In the absence of these animal hosts, stable flies will bite humans and dogs. Filth flies like stable flies exploit habitats and food sources created by human activities such as farming. Stable flies can also be referred to a biting house fly due to their similarity in appearance of house flies. These flies breed in moist, decaying matter. The adult female lives seven to ten days in the field and during this time lays numerous clutches of eggs. A clutch may contain 60-130 eggs. Each female may lay up to 800 eggs in her lifetime, with each clutch requiring a separate blood meal. The average stable fly life cycle in the field ranges from 12-20 
days depending on environmental conditions. Adults can fly within one hour after emerging and will be ready to mate three to five days later (Veterinary Entomology, 2015). Once mated, the females will start to lay eggs five to eight days post-emergence. Unlike many other blood feeding fly species, both sexes feed on blood. The females feed on blood to obtain more protein for egg production and the male survives on sugar alone. Stable flies are diurnal feeding on their hosts during the early morning and late afternoon in warm weather and in the middle of the day during cooler weather. Irritation by the stable fly biting cause cattle to consume less feed, to grow at a slower rate and to convert less feed into body mass. The bunching behavior exhibited by dairy cattle will lead to increased body temperatures lower milk production. The effects are greater when the weather is hot and humid; the bunching interferes with the animals' ability to dissipate excess heat .Stable flies have a negative impact on beef production costs by affecting the required amount of time and feed needed to reach slaughter weight. Losses in feedlots will likely occur when the average number of stable flies per leg is 3 or more (Cilek and Knapp, 1994).

\section{Horn Fly}

The horn fly, haematobia irritans, is considered to be one of the most economically damaging pests of pastured cattle. (Steelman 1976, Drummond 1987). Annual economic losses from horn fly infestations for cattle production in the United States have been estimated to be \$876 million (Kunz et al. 1991). Losses in profitability occur in cow-calf production because of the indirect reduction in calf weaning weight associated with blood feeding activity on cows (Campbell 1976, Kunz et al. 1984, Quisenberry and Schreiber et al. 1987). Annoyance from the flies can not only cause a disruption in milk production, but also with rate of gain and feed efficiency (Campbell 1976, Kinzer et al. 1984). 
Both male and female flies spend their entire life on the host, feeding 24-38 times/day by inserting their proboscis into the hides of cattle (Artigas, 1994; Foil and Hogsette, 1994). The pain inflicted by their bites and their mere presence produce defensive reactions in the host (Foil and Hogsette 1994). Movements, such as walking, tail switching, and head tossing, are taken to rid themselves of horn flies and result in decreased weight gain and production as such movements deplete the stored energy reserves of the cattle (Boland et al. 2008). Steelman et al. (1991) reported that each 100 horn flies on the cow caused an $8.1 \mathrm{~kg}$ per calf reduction in weaning weight (WW). Large infestations of horn flies, which tend to occur from early spring to mid-summer, can also result in significant blood loss and wounds that can lead to secondary infections and damaged hides (Kaufman et al. 2013). As with many blood feeding arthropods, there is also the threat of disease transmission. Horn flies are known vectors for pathogens that cause skin disorders in cattle and are also suspected in the transmission of anthrax, anaplasmosis, and other diseases between herds (Fitzpatrick and Kaufman 2012).

\section{Methods of Fly Control}

Controlling flies in the United States is time consuming and costly, but failure to implement management can lead to decreased weight gain and even weight loss. As such, it is critical to have a management plan for fly control in your herd.

There are many different options producers may choose to use for fly control. Traditionally, producers choose to take the route of chemicals. These can be divided into three main groups, namely anthelmintics (mainly comprising levamisole, morantel, closantel, and a suite of benzimidazoles), ectocides (consisting of organophosphates, synthetic pyrethoids, and a group of biological parasiticides; commonly referred to as insect growth regulators), and 
endectocides (macrolactones). However, there are multiple options deriving from these groups as well as alternatives (Williams, 2005).

\section{Breeding}

Unlike typical fly control methods that mainly rely on chemical use, researchers have investigated fly control through means of breeding. Brown et al. (1992) used horn fly population density on 215 beef cows representing seven breed groups and 51 sires were used to obtain estimates of repeatability (rXX) and heritability (h2) for resistance to the horn fly. The estimate of $\mathrm{rXX}$ was $.47+/-.02$. Estimates of h2 were $.78+/-.16$ and $.59+/-.10$. These estimates suggest the possibility of selection procedures as an environmentally safe alternative to the use of chemical control.

Steelman et al. (1991) noticed differences in the total number of flies based on breed. Statistically significant differences were observed in the population density of the horn fly on different breeds of beef cattle. The European breed Chianina had a population density of horn flies generally $\leq 50 \%$ than that of the British cattle breeds (Angus, Hereford, Polled Hereford, and Red Poll) and another European breed (Charolais). Each 100 flies per cow caused a reduction of $8.1 \mathrm{~kg}$ in calf weaning weight (Steelman et al., 1991). Cows within each breed with low numbers of horn flies weaned significantly heavier calves than cows with higher numbers of horn flies (Steelman et al., 1991).

The efficacy of Brahman breeding used as an alternative tactic to manage insecticideresistant populations of adult horn flies has been used. Mean fly counts on Brahman $\times$ Angus cows were approximately intermediate to the two purebred mean fly counts. Brahman breeding caused significant reductions in the number of organophosphate-resistant horn flies, which had been equal to or greater than that obtained from continued spraying with organophosphate insecticides. The Brahman $\times$ Hereford cows, which have one-eighth greater Brahman breeding 
than the Brangus cows, had fewer horn flies on 48 of 56 sampling dates in 1988-1990 and significantly fewer flies on 37 sampling dates (Steelman et al. 1994). The effectiveness of Brahman breeding in causing lower numbers of insecticide-resistant horn flies significantly increased as the percentage of Brahman breeding increased (Steelman et al. 1994). Although an alternative method, this is not practical for all producers as Brahman cattle do not thrive well in a multitude of environments and lack substantial production traits that conventional Bos Taurus cattle possess. Repeatability and heritability may however, be a potential avenue for fly control in the future.

\section{Sprays}

Sprays are typically used to target stable flies as their primary feeding site is on the legs of cattle because treatment devices such as dust bags and insecticide impregnated ear tags do not effectively treat this area. Campbell and Hermanussen (1971) tested different insecticides as residual sprays, four as animal sprays and two as area sprays for stable flies. Of the residual sprays, only Shell SD-8447 (2-chloro-1-(2,4,5-trichlorophenyl) vinyl dimethyl phosphate) applied at a rate of $1.3 \mathrm{oz} / 1000 \mathrm{ft}^{2}$ reduced infestations $50 \%$ or for 2 weeks or longer. Of the animal sprays, $0.5 \%$ dilutions of ronnel as $25 \% \mathrm{EC}(1 / 4 \mathrm{gal} / \mathrm{cow})$, crotoxyphos 67 as $46.7 \%$ EC (1/2 gal/cow), and methoxychlor $50 \mathrm{wp}(1 / 4 \mathrm{gal} / \mathrm{cow})$ reduced stable flies $75 \%$ or more at 1 day posttreatment, but only crotoxyphos and methoxychlor reduced populations $50 \%$ or more at 4 days posttreatment; however, after 7 days the number of flies on all treated animals was equal to or greater than the number on the untreated control herd. It was concluded that sprays were rubbing off once cattle entered wet pastures and/or water.

Hogsette et al. (1991) used insecticide sprays in two different treatment groups as an alternative to fly tags against horn fly populations on cow-calf pairs and yearling heifers in northwest Florida. Treatment 1 consisted of pesticides applied to cows and calves at the 
minimum treatment interval designated on the pesticide labels. Treatment 2 consisted of pesticides applied to cows and calves only when the average weekly horn fly count exceeded 50 flies per head. However, time between applications was never less than the minimum treatment interval stated on the pesticide label. Insecticides used were; Lintox (dioxathion 10.5\%, vapona 0.5\% ), D Ra-Vap (rabon 23.0\%, vapona 5.7\%) Co-Ral (coumaphos 11.6\%), Methoxychlor (methoxychlor 24.8\%), Prolate (phosmet 11.6\%) and Del-Tox (dioxathion 20.4\%). However, they were unable to maintain horn flies below a level of 50 flies per animal on cow-calf pairs. Fly populations were effectively reduced, but this reduction did not significantly influence cow and calf weights and cow condition score. Data indicate that the economic injury level exceeds seventy 200+ fly days. They concluded that neither of the spray regimens would be practical for commercial use, especially with no indication of increased net returns. Less strenuous regimens would certainly be counterproductive. Therefore, it can be concluded that although sprays may provide relief, it is only temporary and can be time consuming depending on the area being grazed and the number of head.

\section{Pour Ons}

Pour-on insecticides are ready-to-use formulations applied along the back line of cattle. Although pour-ons will control flies for short periods, the stress in cattle in using this method may offset the benefits of the fly control. Many pour-on insecticides are synthetic pyrethoids, however, a few pour-on insecticides are macrocyclic lactones (ivermectin, etc,). Common products of use are: permethrin (many brand names), macrocyclic lactones (ivermectin and related compounds), and spinosad (Elector). Leak et al. (2009) monitored fly populations using a synthetic pyrethroid insecticide. Treatments were given as 'pour-on' applications along the backlines of animals, using automatic drench-gun applicators. This not only resulted in a decline of $93 \%$ in the apparent density of the Tstete fly, but the numbers of Stomoxys and Tabanidae 
(horse fly) were also significantly reduced $(\mathrm{P}<0.01)$. Marley (1993) found that Late spring treatment of cattle with a single dose of pour-on ivermectin $\left(0.5 \mathrm{mg} \mathrm{kg}^{-1}\right.$ body weight $)$ resulted in reduced horn fly populations for approximately 6 weeks, with percentage efficacy exceeding $80 \%$ for at least 26 days post-treatment. Although not as commonly used, pour ons can result in reduction of fly populations. However, the stress caused during handling and the amount of time required to administer pour ons may outweight the results when performed as the sole point in time of the management scheme.

Additionally, misuse of pour ons has been said to lead to reproductive issues in bulls. Dohlman et al (2015) looked at reproductive parameters in peripubertal Angus bulls using a commonly used pyrethroid pour-on. Results from the study revealed pyrethroid-treated bulls had greater spermatozoa head and midpiece abnormalities compared to controls resulting in higher primary morphological abnormalities. Although some morphological semen parameters appear to be negatively affected by use of pyrethroid administration in bulls, biological relevance of this result needs to be further elucidated as the ability to pass a breeding soundness exam was not affected.

Stewart et al. (2015) studied the effects of cyfluthrin and pyrethrin spray products used in combination with cyfluthrin pour-on and fly tags on bull sperm motility and serum testosterone concentrations. Angus x Simmental bulls were assigned randomly to one of two treatment groups: 1) pour-on plus fly tags (CONT; $\mathrm{n}=12)$, or 2) pour-on, fly tags, premise spray plus fog spray $(\mathrm{EXP} ; \mathrm{n}=11)$. These results showed no consistent deleterious effects on overall or progressive sperm motility in bulls which received fly tags, pour-on, daily fogging, and weekly premise spray applications (EXP) compared with those which received only fly tags and pour-on products (CONT). Testosterone concentrations were significantly reduced in EXP bulls when 
compared with CONT bulls at week nine, suggesting a delayed effect of the beta-cyfluthrin and pyrethrin spray applications on testosterone production. While these results conclude that these spray applications do not adversely affect sperm motility in the short-term (nine weeks), the authors suggest that additional studies were needed to determine the long-term effects of these application methods on semen quality.

\section{Dust Bags}

Campbell (1976) found horn fly control (97\%) was achieved by forced use of dust bags (June 1 to Oct. 30). The average steer calf weaning weight from cows using dust bags was $386.66 \mathrm{lb}$ as opposed to $373.74 \mathrm{lb}$ for calves from the cows with no fly control. The $12.92 \mathrm{lb}$ difference was significant at the 0.05 level of probability (T test). Additonally, Harvey and Brethour (1979) found horn flies were controlled by exposing yearling steers to dust bags containing $1 \%$ coumaphos installed at entrances to salt box enclosures. Weight gains of treated steers during a 6 year period, 1971-1976, increased an avg of 5 and $3 \mathrm{~kg} / \mathrm{head}$ more than untreated steers during early and late grazing periods, respectively. The total gain advantage for horn fly control at time of slaughter, following a feedlot phase, was $10 \mathrm{~kg} / \mathrm{head}(\mathrm{Hogsette}$ et al. 1991).

In a study primarily looking at effects of fly tags, dust bags were also observed. Coumaphos $(\mathrm{CoRal} 囚)$ insecticide dust bags used in a separate herd produced an $86 \%(P<0.05)$ reduction in horn flies and an $18 \%(P>0.05)$ reduction in face flies. In a herd treated with coumaphos dust bags, horn fly control averaged $93 \%(P<0.05)$ and face fly control averaged $34 \%(P>0.05)$. Fourteen-week horn fly control averaged $88 \%(P<0.05)$ with the $10 \%$ PVCtreated tag, 83\% $(P<0.05)$ with the 5\% PVC-treated tag, 71\% $(P>0.05)$ with the 5\% polyurethane-treated tag and 74\% $(P<0.05)$ with coumaphos dust bags (Williams et al. 1981). 
From these studies, it can be concluded that dust bags are effective in reducing horn flies, however may not be as effective on other fly populations like face flies.

\section{Fly tags}

Pesticide-impregnated ear tags continue to be a popular choice for control of horn flies on cattle despite resistance development. When first introduced commercially, tags kept horn fly populations far below the economic injury level of 50 per animal (Butler 1975) for several months (Ahrens \& Cocke 1979, Knapp \& Herald 1981, Williams et al. 1981, Miller et al. 1984). Similarly, Swiger and Payne (2016) evaluated the efficacy of ear tags against horn fly populations over a two year period and determined if reduced fly density results in economic return. In 2013, treated cows averaged fly reductions of $198(\mathrm{~s}=38.91 ; n=3)$ for macrocyclic lactone treatments, $175(\mathrm{~s}=62.74 ; n=4)$ for pyrethroid treatments, and $174(\mathrm{~s}=35.28 ; n=8)$ for organophosphate treatments compared with untreated animals $(214 ; \mathrm{s}=50.38 ; n=9)$. During 2014, mean fly reductions were $187(\mathrm{~s}=14.15 ; n=4)$ for macrocyclic lactone, 147 $(\mathrm{s}=61.41 ; n=13)$ for pyrethroid, and $143(\mathrm{~s}=77.16 ; n=8)$ for organophosphate treatments relative to the untreated $(200 ; \mathrm{s}=99.83 ; n=14)$. It was concluded that treatment of cattle with ear tags significantly reduced horn fly numbers compared with untreated cattle.

Sanson et al. (2003) looked at the effects of horn fly control on body weight gain of yearling Angus-Brangus cross heifers and were evaluated in three separate studies during the years 1999, 2000 and 2002. In all three studies, the tag treatment (10\% lambdacyhalothrin+13\% piperonyl butoxide impregnated ear tags) provided excellent horn fly control. In the three studies, the average weekly horn fly counts for tagged heifers were 1,3 , and 0 flies per side while the average on untreated heifers was 52, 163 and 90 flies per side. In studies 1 and 2, there was no difference $(P>0.1)$ in weight gain between tagged and untreated heifers, but in study 3 , tagged heifers gained 50\% more weight $(P<0.001)$ than the untreated heifers. 
Knapp and Herald (1984) reported that tagging of all beef cows and calves in a herd with one $8 \%$ fenvalerate ear tag per ear during early spring resulted in an average of $90 \%$ reduction of face flies, Musca autumnalis over a 21-week period. In another test, tagging of lactating dairy cows with one tag per ear, with a portion of the herd left untagged during a 7-week period in the middle of the test, resulted in an average of $86 \%$ reduction of face flies over an 18-week period. Seasonal control of the horn fly was achieved in both treated herds, even when one-third of the dairy cows were not tagged. Some repellency of the face fly by the treatment was noticed

\section{Resistance}

For the past few decades, pyrethroids have become the leading global insecticide used in animal agriculture, including animal products, because of the phasing out of the more ecologic harmful products such as organophosphates and carbamates. In the beef industry, many producers and veterinarians use pyrethroid-based insecticide products to improve productivity in cow-calf operations by eliminating potential insect-borne diseases and to control biting flies. According to the USDA National Animal Health Monitoring System, over one-half of beef operations used some type of insecticide fly control, and over $70 \%$ of larger herds (greater than 50 head) used insecticides to control production losses due to disease transmitting pests. However, horn flies soon became resistant to stirofos and pyrethroids, and ear tags are no longer recommended for use in horn fly management programs in some parts of the United States (Sheppard 1983, 1984; Harvey et al. 1984; Quisenberry et al. 1984; Kunz \& Schmidt 1985; Schmidt et al. 1985).

Horn flies controlled for $2 \mathrm{yr}$ with $8 \%$ fenvalerate tags were difficult to control in the third year (1981) at the University of Georgia Alapaha Experimental Range (AER). Field data showed progressively poorer control over a 4-yr period which stabilized in the fifth year (1983). Very poor horn fly control was realized with 7.5\% flucythrinate (another pyrethroid) cattle ear 
tags when used for the first time in 1983 at AER. Flucythrinate tags gave very good horn fly control at two other sites in 1983 where pyrethroid use had been limited (Sheppard, 1984).

Additonally, Cilek and Greene (1994) found insecticide resistance to two organophosphates, dichlorovos and stirofos, and a pyrethroid, permethrin, was detected in stable flies collected from eight cattle feedlots in southwestern Kansas. The frequency of resistant stable flies ranged from 2 to $100 \%$ depending on population and insecticide tested. No resistance was detected to the chlorinated hydrocarbon methoxychlor. Generally, the prevalence of resistance in each fly population in decreasing order was dichlorvos $>$ stirofos $>$ permethrin. Resistant stable flies were found in some feedlots where insecticide use was absent or minimal (i.e., application once per year or less) and was suspected to have resulted from localized dispersal of insecticide-resistant flies from a nearby feedlot. Due to the developing resistance, alternative methods have gained popularity.

\section{Insect growth regulators}

Numerous chemicals act as parasite-control agents by disrupting insect development. However, relatively few of these have been registered for veterinary use, and little is known about their ecotoxicity. One insect growth regulator of growing popularity is methoprene. Miller et al. (1974) found that methoprene fed to cattle at a rate of $1 \mathrm{mg} / \mathrm{kg}$ body weight gave essentially complete control of face flies, and a rate of $2.5 \mathrm{mg} / \mathrm{kg}$ body weight gave significant control of house flies. The IGR in Altosid® IGR (methoprene) mimics naturally occurring insect biochemicals that are responsible for insect development. Through this mimicry, Altosid® IGR keeps the horn fly larvae from developing into adult flies that would otherwise emerge from the manure. It is able to exert this effect at very small concentrations. Additonally, Altosid® added to feed through minerals is less labor intensive. Thus, it is a more ideal fly control choice for today's environmentally conscious producer. Thus, the experiment in this study will evaluate the 
feeding of feed through medicated mineral containing Altosid® IGR and its effect on calf growth.

\section{Section 2: Materials and Methods}

\section{Animals and Housing}

Cattle used in this project were born and raised at the WVU Reedsville Farm (Reedsville, WV). The farm is located atop the Appalachian Plateau and as an approximate elevation of 548.64 meters. Average age of dam was 4 years with calves being March born and Angus sired. Pairs were grazed in 5 hectare pastures. Animals were provided free choice hay upon grass limitations in plots as well as provided ad libitum access to water.

\section{Experimentation}

Four cow-calf pairs were assigned to one of three treatment types; non-medicated mineral (Southern States Cattleman's Pride Weathershed $\left.{ }^{\circledR} 2: 1\right)$ with no fly control, (NON) nonmedicated mineral (Southern States Cattleman's Pride Weathershed® 2:1)with fly tags (FLY; pyrethoid) and medicated free choice mineral (Cattleman's Pride Fly Stop w/ (Aureo/Altosid ${ }^{\circledR}$ ) containining Altosid® IGR (MED). Forage mass and availability was similar for all treatments. Performance didn't differ based on pasture, thus this was used a replicate. The duration of this study was 64 days (July 7 - September 9, 2014).

\section{Data Collection}

\section{Weather}

Precipitation and temperature for 2014 for the WVU Reedsville Farm were collected via farm staff determining the environment for the fly populations. 


\section{Fly Traps}

Fly traps (Starbar EZ Trap) were placed in each plot in close proximity to waterers. Fly traps were roughly collected weekly, with exception to the third week. Fly load was lower during this time point, thus collection and implement of previous traps was not necessary. Thus fly trap collection dates were days 9, 16, 31, 37, 44, 58 and 64. Upon collection, the six flies (blow, flesh, house, face, stable and horn) were identified and recorded.

\section{Facial Counts}

Facial pictures were captured of all cows and calves. Total fly counts were determined visually and recorded. Pictures occurred in the beginning (days 2 and 3), middle (days 31 and 32) and end (day 64) of the study. Pictures were taken at 0900 hours on the listed days.

\section{Body Weights}

Body weights for both cows and calves were collected on day 1 (beginning), day 28

(middle) and day 64 (end). Average daily gain was determined for Period 1 (day 1-28), Period 2 (day 28-64) and overall for both cows and calves.

\section{Statistical analysis}

Data were analysis using the GLM procedures of SAS. Fixed effects included treatment and time. Significance was accepted at $P<0.05$. 


\section{Section 3: Results}

\section{Weather}

Average temperature for 2014 was $13.0^{\circ} \mathrm{C}$. Additionally, rainfall for 2014 was relatively

high with $8.4 \mathrm{~cm}$ for the summer months. (Figure 3).

\section{Mineral Intake}

Mineral intake was similar between treatments (0.39/d) [Figure 4].

\section{Determination of Fly Load}

\section{Fly Traps}

There were no treatment effects $(P>0.11)$ on fly type found on the fly traps. (Figure 4$)$.

Numerically, more flesh, face and house flies were observed on the traps. However, there was a time effect from days 9 to $16(P<0.001)$, days 16 to $31(P<0.001)$ and days 44 to $58(P<0.001)$ [Figure 5].

\section{Facial Counts}

There were no treatment effects on cow and calf facial fly counts on days $2(P=0.16$; $P=.50), 31(P=0.49 ; P=0.13)$ and $63(P=0.73 ; P=0.27)$, respectively. However, there were treatment effects on cow-facial-counts on day 32 (MED 14, NON 8, FLY 5; $P<0.01$ ), and calffacial-counts on days 3 (MED 6, NON 7, FLY 4; $P=0.02$ ) and 32 (MED 16, NON 15, FLY 5; $P=0.01)$ [Figures 6 and 7].

\section{Effect of treatment of body weight gain}

There were no treatment effects on calf ADG period1 (1.13 kg/d; $P=0.93)$, period2 (1.06 $\mathrm{kg} / \mathrm{d}, P=0.28)$ and overall $(1.09 \mathrm{~kg} / \mathrm{d} ; P=0.19)$ [Figure 8]. There were no treatment effects on cow ADG during period $1(-0.41 \mathrm{~kg} / \mathrm{d} ; P=0.13)$ or period $2(-0.29 \mathrm{~kg} / \mathrm{d} ; P=0.35)$. However, 
there was a trend $(P=0.08)$ for a treatment effect on cow ADG overall. Cows on the fly treatment lost more BW than the other two treatments (MED -0.1, NON -0.2, FLY -0.7). Numerically, cows offered mineral with Altosid® IGR lost the least amount of weight (MED 0.1, NON -0.2, FLY -0.7) [Figure 9]. 


\section{Section 4: Discussion}

Although not statistically different, tendencies in the results show that feed through mineral containing Altosid ${ }^{\circledR}$ has the potential to reduce fly load, by specifically targeting the horn fly population. Although, ADG of calves did not between treatment types it is likely that this was due to weather as well as fly load. Flies thrive more abundantly in warm wet environments and temperatures for this area were relatively low (cooler) resulting in a lower fly load. In participular horn fly population. Thus, not only were fly populations not large enough to cause a major disruption in the cow-calf pairs, but horn fly numbers were not high enough for mineral containing Altosid ${ }^{\circledR}$ to have a significant effect on fly emergence. However, research has shown methoprene is an effective tool for fly control. Miller et al. (1978) found when methoprene was fed to grazing cattle in a block formulation at an average rate of $0.54 \mathrm{mg} \mathrm{AI} / \mathrm{kg}$ body wt, populations of Musca autumnalis were reduced. In 1976, when methoprene was fed to similar cattle in a loose mineral supplement at an average rate of 0.07 or $0.13 \mathrm{mg} \mathrm{AI} / \mathrm{kg}$ body wt, $45-90 \%$ of face fly pupae did not enclose, but counts of adults on the cattle were not reduced markedly. In both years, counts of adult horn flies were lower on the treated herd than on the check herd. Additonally, Wijayaratne et al. (2011) found methoprene concentrations to be effective on other pests. Methoprene levels will decline with time following its application. However, methoprene can reduce populations of red flour beetles (T. castaneum) by reducing their progeny production even if adults do emerge. However, more research needs to be conducted to further support mineral containing methoprene as an effect fly management practice. Additionally, fly populations in different environments need to be explored in order to determine and treat horn fly populations in different climates. 


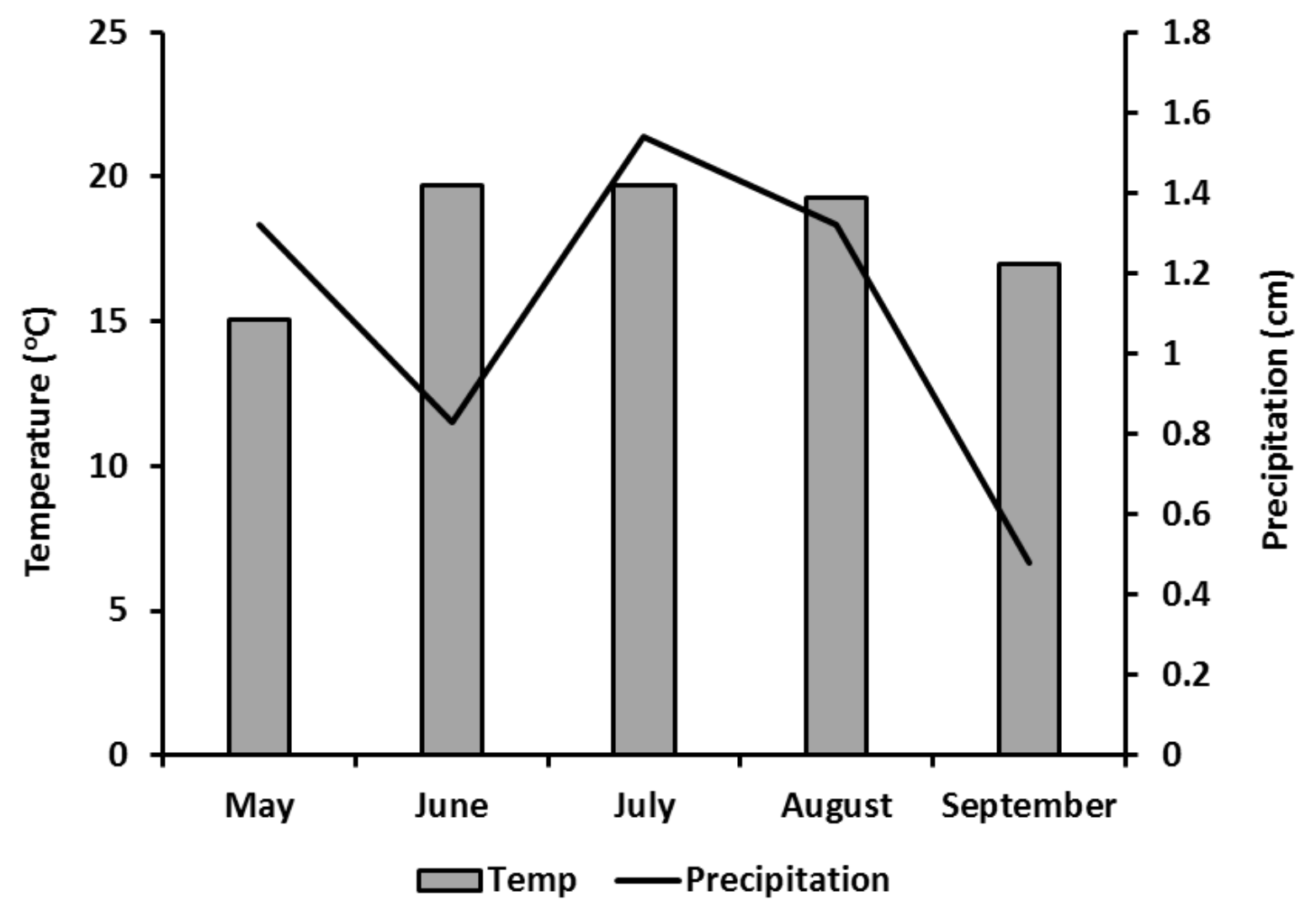

Figure 3. Weather data

Weather data from WVU Reedsville farm for 2014 . Temperature $\left({ }^{\circ} \mathrm{C}\right)$ is represented on the left $\mathrm{y}$-axis and precipitation $(\mathrm{cm})$ on the right $\mathrm{y}$-axis. 


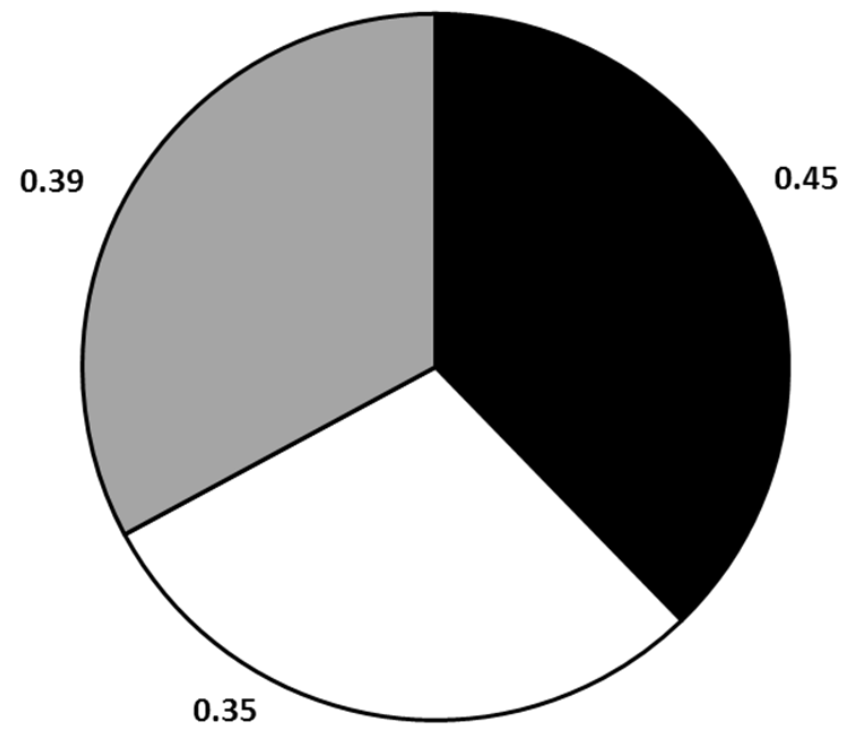

—Med №n afly

Figure 4. Average mineral intake for the three treatment groups. 


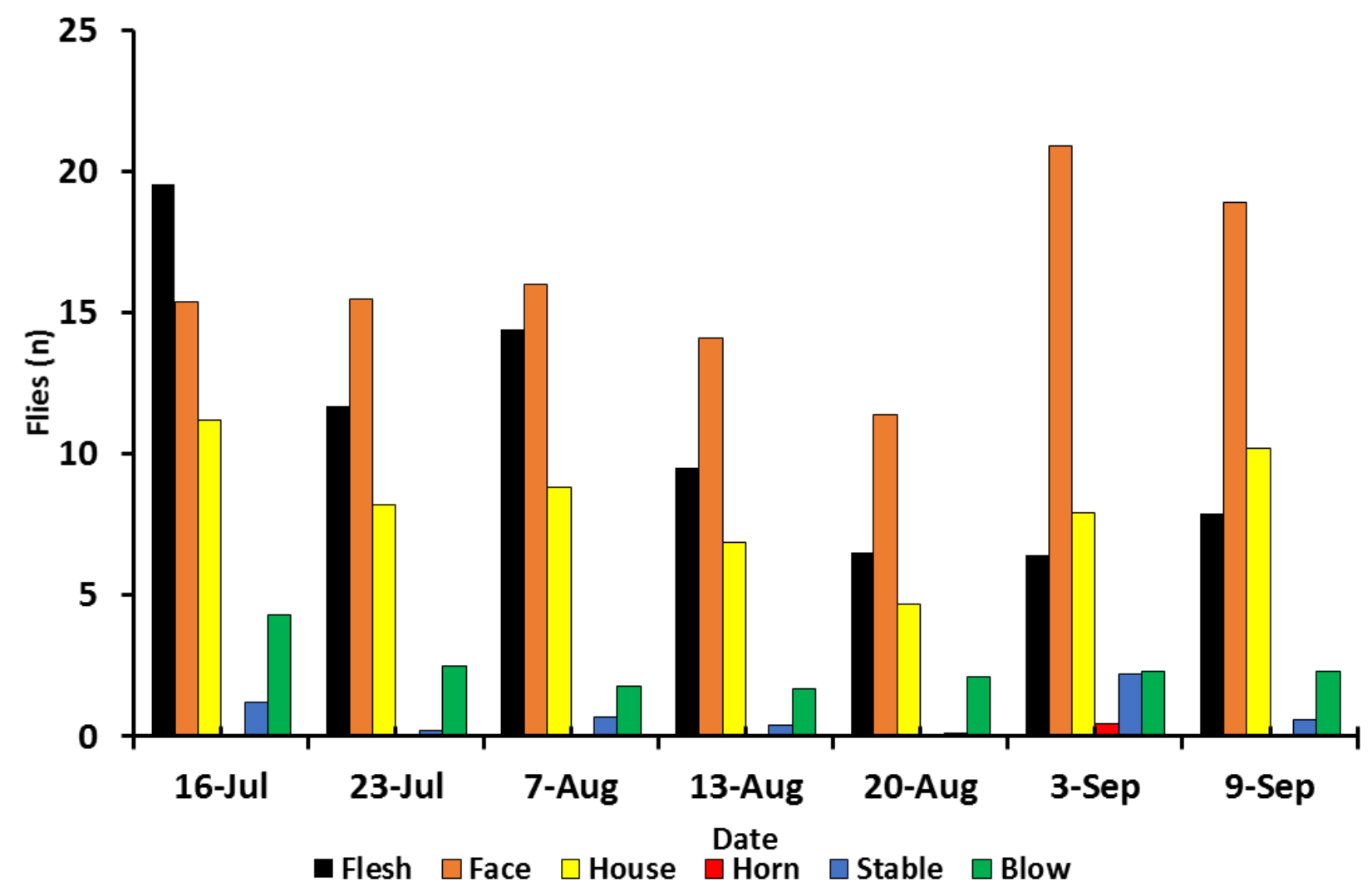

Figure 5. Fly species determined by fly traps analyzed by date.

There was a time effect from 16-Jul \& 23-Jul (days 9-16; $P<0.001$ ), 16-Jul-20-Aug (days 16 to $31 ; P<0.001$ ) and 3 -Sept \& 9 -Sept (days 44 to $58 ; P<0.001$ ). 


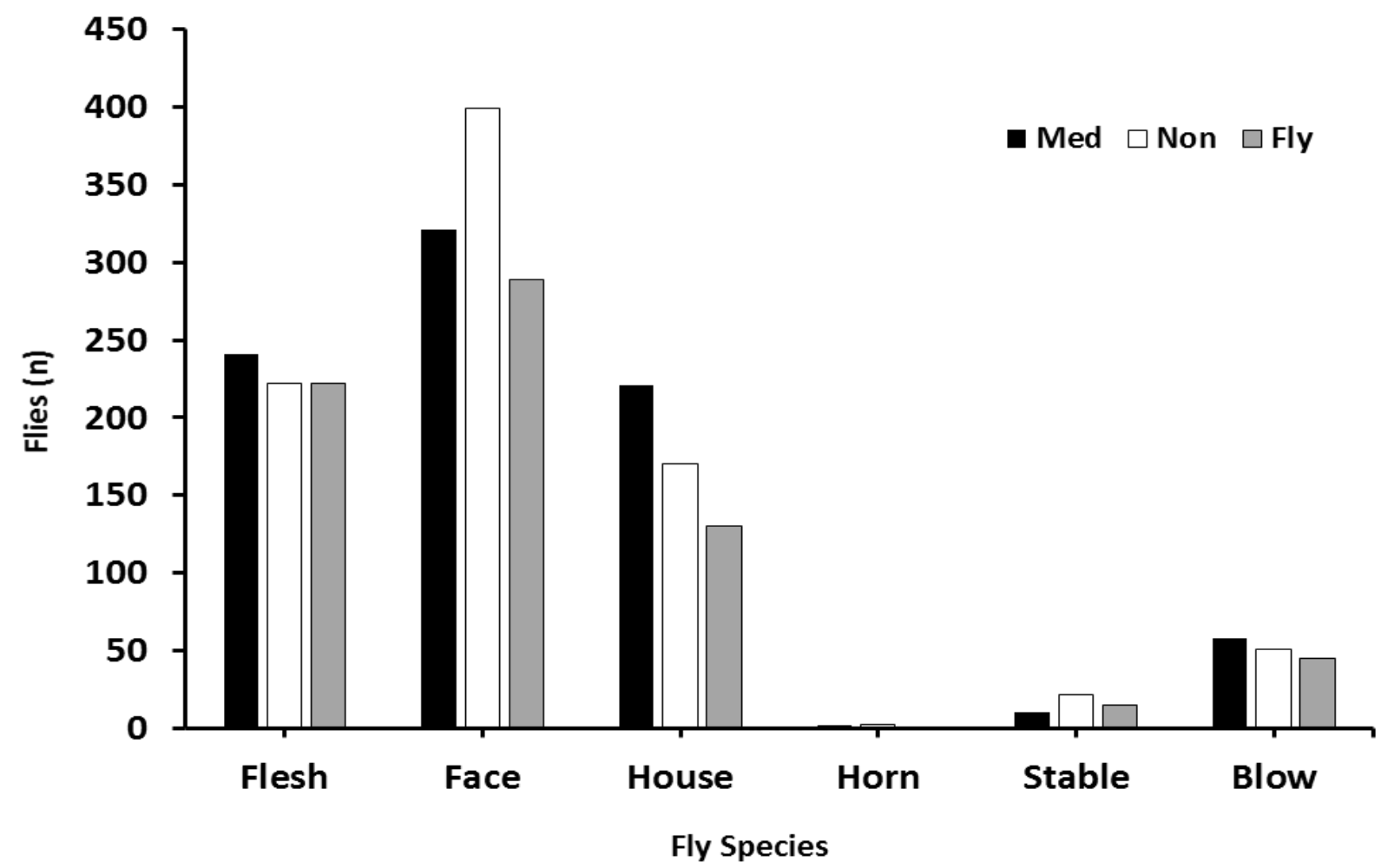

Figure 6. Fly species determined by fly traps for each treatment type.

There were no treatment effects on fly types observed when measured on fly traps $(\mathrm{P}>0.11)$. 


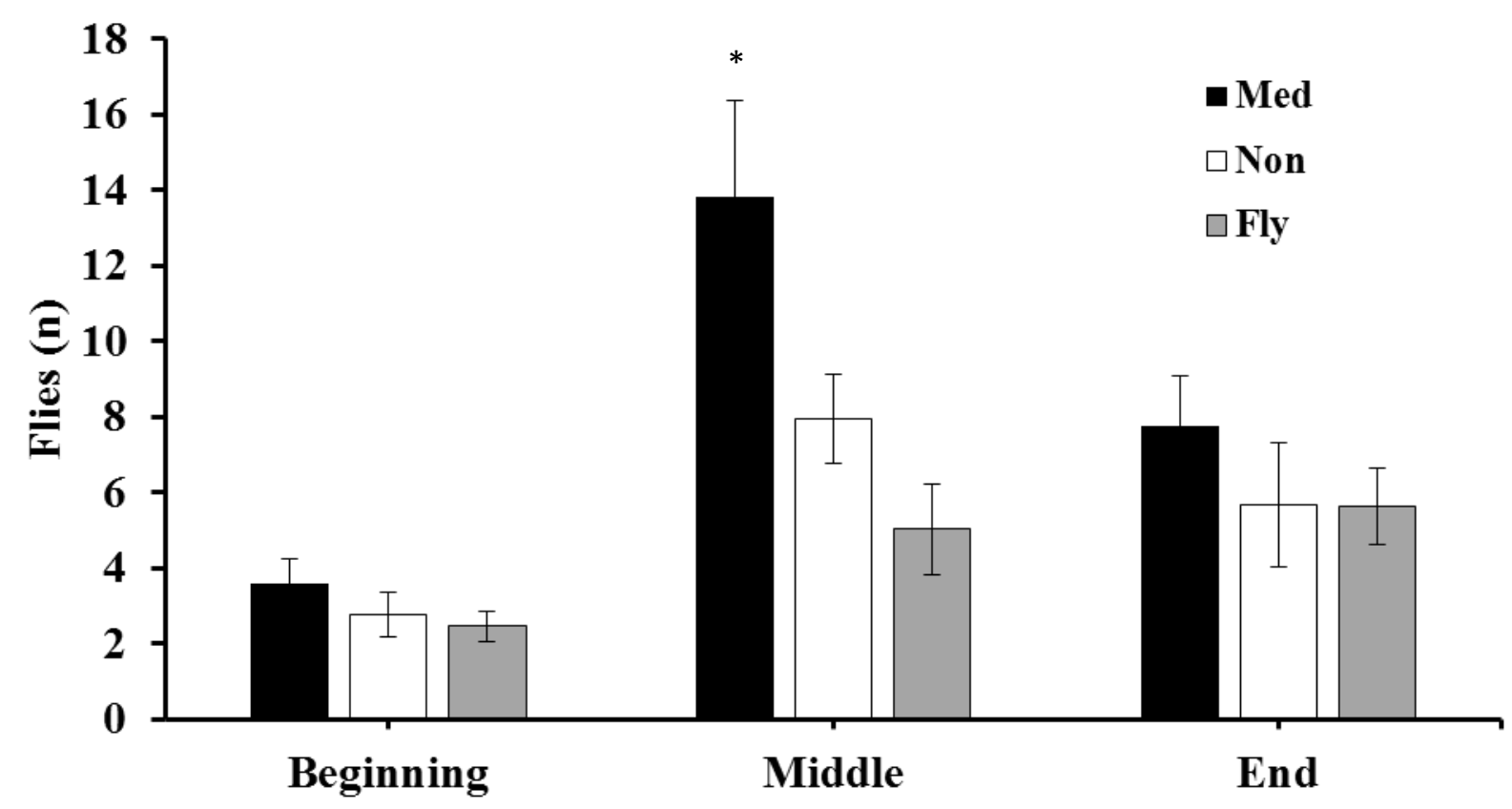

Figure 7. Facial fly counts for cows of the three treatment groups based on photography.

No significant differences occurred for in the beginning or end $\mathrm{P}>0.05$. However, a treatment effect occurred on day 32 (Middle; $\mathrm{P}<0.01$ ). 


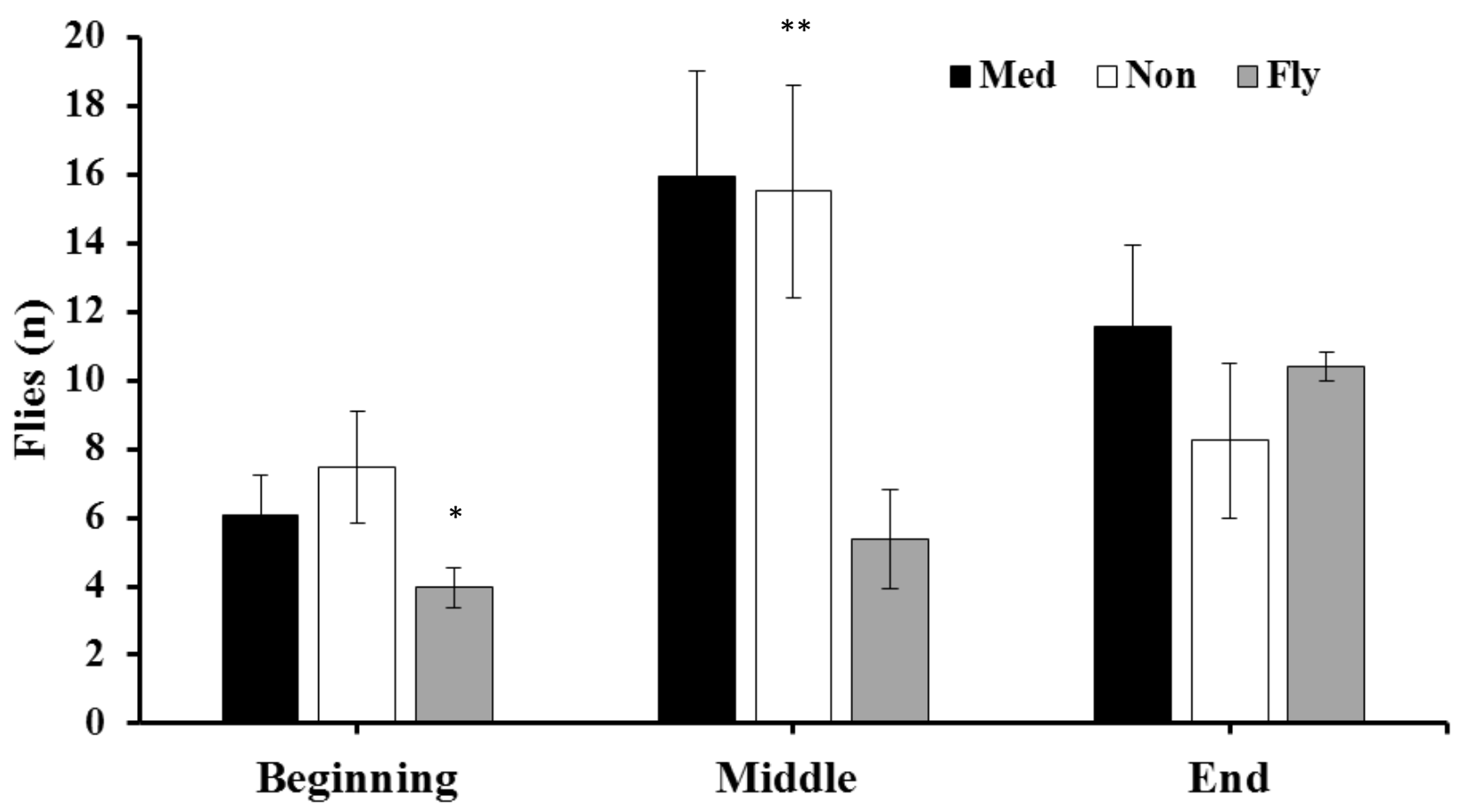

Figure 8. Facial fly counts for calves of the three treatment groups based on photography. Treatment effect occurred on days 3 (Beginning; $\mathrm{P}=0.02$ ) and 32 (Middle; $\mathrm{P}=0.01$ ) 


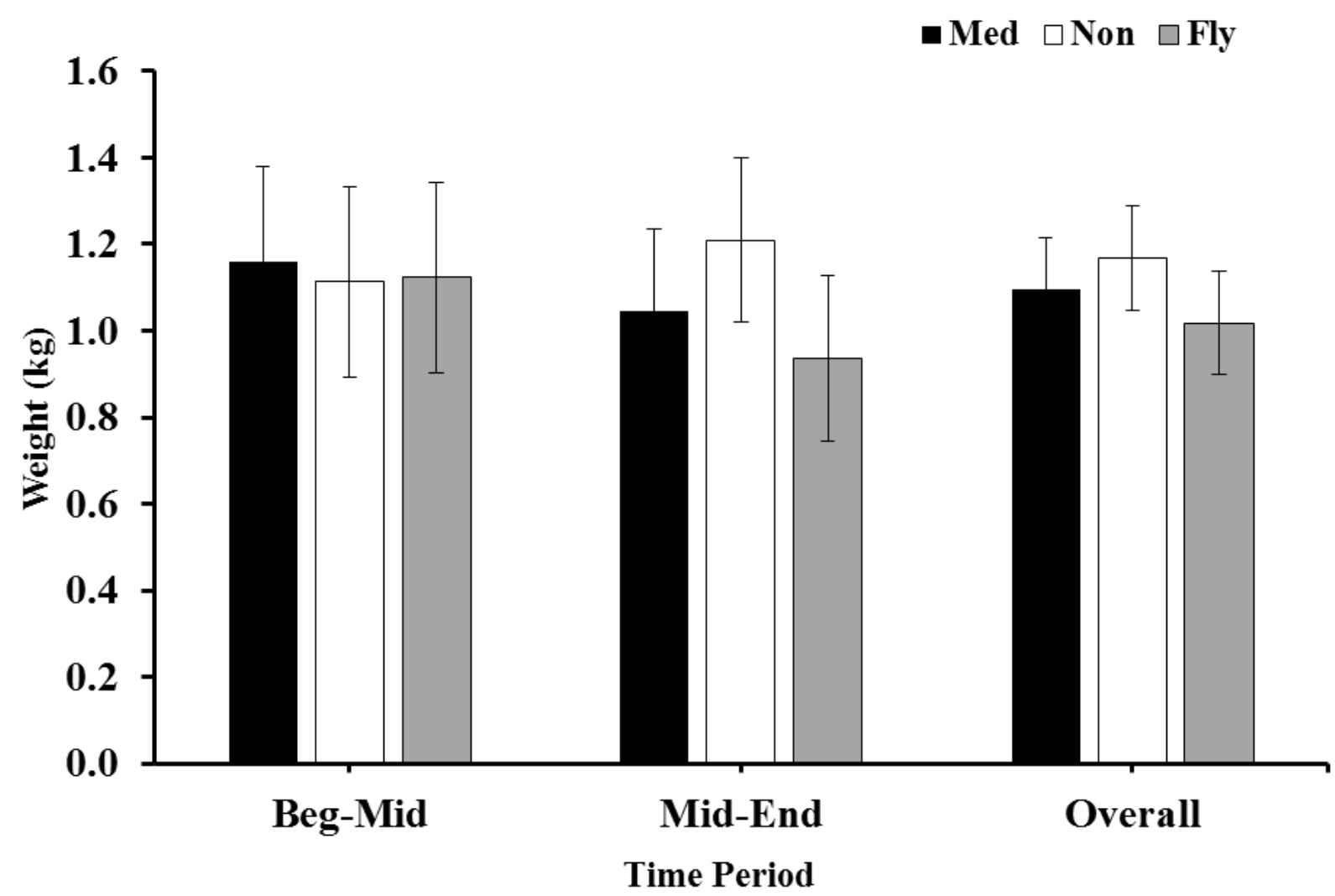

Figure 8. Calf average daily gain

There were no treatment effects on calf ADG period $1(1.13 \mathrm{~kg} / \mathrm{d} ; P=0.93)$, period $2(1.06 \mathrm{~kg} / \mathrm{d}$, $P=0.28)$ and overall $(1.09 \mathrm{~kg} / \mathrm{d} ; P=0.19)$. 


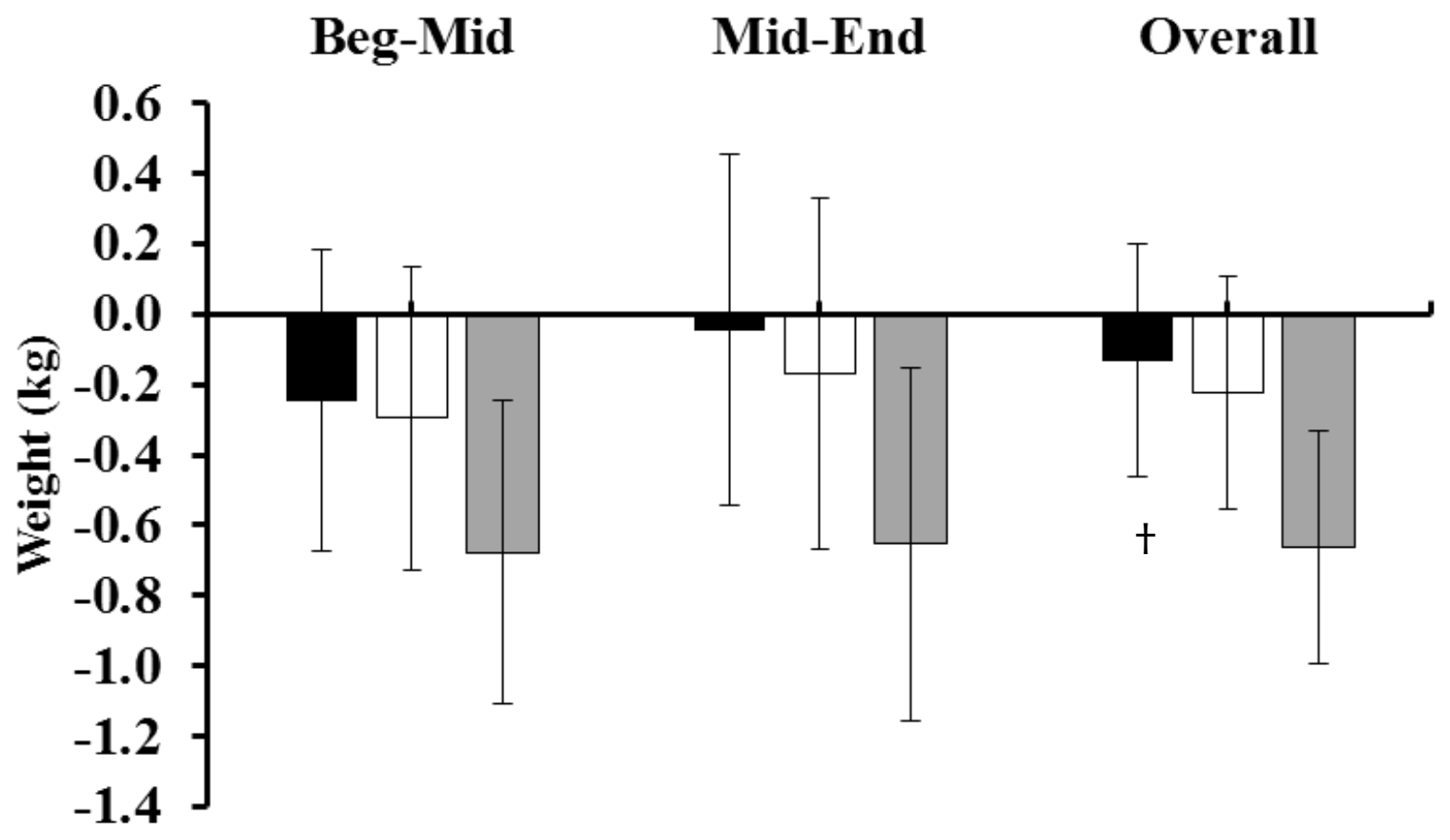

- Med $\square$ Non $\square$ Fly

Figure 9. Change in cow body weight

There were no treatment effects on cow ADG during period $1(-0.41 \mathrm{~kg} / \mathrm{d} ; P=0.13)$ or period2 ($0.29 \mathrm{~kg} / \mathrm{d} ; P=0.35)$. However, there was a trend $(P=0.08)$ for a treatment effect on cow ADG overall. Cows on FLY (non-medicated with fly tags) lost more BW than the other two treatments. 


\section{Literature Cited}

Brown, A. H., C. D. Steelman, Z. B. Johnson, C. F. Rosenkrans, and T. M. Brasuell. 1992. Estimates of repeatability and heritability of horn fly resistance in beef cattle. J. Anim. Sci. 70:1375-1381.

Buxton, B.A., Hinkle, N.C., Schultz, R.D., 1985. Role of insects in the transmission of bovine leukosis virus: potential for transmission by stable flies, horn flies, and tabanids. AVJR. 46, $123-126$.

Boland, H.T., Scaglia, G., Umemura, K., 2008. Case study: impact of horn flies, Haematobia irritans (L.) (Diptera: Muscidae), on the behavior of beef steers. ARPAS. 24, 656-660.

Byford, R.L., Craig, M.E., Crosby, B.L., 1992. A review of ectoparasites and their effect on cattle production. J. Anim. Sci. 70, 597-602

Campbell, J. B., and J. F. Hermanussen. 1971. Efficacy of insecticides and methods of insecticidal application for control of stable flies in Nebraska. J. Econ. Entomol. 54: 11881190.

Campbell, J. B. 1976. Effect of Horn Fly Control on Cows as Expressed by Increased Weaning Weights of Calves. J. Econ. Entomol. 69:711-712.

Catangui MA, Campbell JB, Thomas GD, Boxler DJ. 1997. Calculating economic injury levels for stable flies (Diptera: Muscidae) on feeder heifers. J. Econ. Entomol. 90: 6-10.

Cilek, J.E. and F.W. Knapp. 1994. J Med Entomol. 31 (5): 760-762.

Dohlman, T. M., P. E. Phillips, D. M. Madson, C. A. Clark, and P. J. Gunn. 2016. Effects of label-dose permethrin administration in yearling beef cattle: I. Bull reproductive function and testicular histopathology. Theriogenology 85:1534-1539.

Harvey, T.L., Launchbaugh, J.L., 1982. Effect of horn flies on behavior of cattle. J. Econ. Entomol. 75, 25-27.

Harvey, T. L., and J. R. Brethour. 1979. Effect of Horn Flies on Weight Gains of Beef Cattle. J. Econ. Entomol. 72:516-518.

Hogsette, J. A., D. L. Prichard, and J. P. Ruff. 1991. Economic Effects of Horn Fly (Diptera: Muscidae) Populations on Beef Cattle Exposed to Three Pesticide Treatment Regimes. J. Econ. Entomol. 84:1270-1274.

Huddleston, E.W., Lavigne, R.J., Ueckert, D.N., Watts, J.G., 1974. Rangeland entomology. Society for Range Management, Littleton, CO, USA (127 pp.).

Knapp, F. W., and F. Herald. 1981. Face Fly and Horn Fly Reduction on Cattle with Fenvalerate Ear Tags. J. Econ. Entomol. 74:295-296. 
LaBrecque GC, Meifert DW, Weidhaas DE. 1972. Dynamics of house fly and stable fly populations. Florida Entomologist 55: 101-106.

Marley, S. E., R. D. Hall, and R. M. Corwin. 1993. Ivermectin cattle pour-on: duration of a single late spring treatment against horn flies, Haematobia irritans (L.) (Diptera: Muscidae) in Missouri, USA. Vet Parasitol. 51:167-172.

Miller, R. W., and E. C. Uebel. 1974. Juvenile Hormone Mimics as Feed Additives for Control of the Face Fly and House Fly. J. Econ. Entomol. 67:69-70.

Miller, R. W., L. G. Pickens, and L. M. Hunt. 1978. Methoprene: Field Tested as a Feed Additive for Control of Face Flies. J. Econ. Entomol. 71:274-278.

Norris, K. R. 1965. The Bionomics of Blow Flies. Annual Review of Entomology Annu. Rev. Entomol. 10:47-68.

Sanson, D.W., A.A DeRosa, G.R Oremus and L.D Foil. 2003. Effect of horn fly and internal parasite control on growth of beef heifers, Veterinary Parasitology, (117), 4:291-300.

Steelman, C. D., A. Hayden Brown jr., E.E. Gbur and G. Tolley. 1991. Interactive Response of the Horn Fly (Diptera: Muscidae) and Selected Breeds of Beef Cattle. (84) 4: 1275-1282.

Steelman, C.D., R. W. McNew, M. A. Brown, G. Tolley, J. M. Phillips. 1994. Efficacy of Brahman Breeding in the Management of Insecticide Resistant Horn Flies (Diptera: Muscidae) on Beef Cattle. J. Econ. Entomol.. (87). 1:7-14.

Stewart, J., C. Shipley, F. Ireland, V. Jarrell, C. Timlin, D. Shike, and T. Felix. 2016. Long-term Effects of Pyrethrin and Cyfluthrin, a Type II Synthetic Pyrethroid, Insecticide Applications on Bull Reproductive Parameters. Reproduction in Domestic Animals 51:680-687.

Swiger, S. L., and R. D. Payne. 2016. Selected Insecticide Delivery Devices for Management of Horn Flies (Haematobia irritans) (Diptera: Muscidae) on Beef Cattle. J Med Entomol.

Sheppard, D. C. 1984. Fenvalerate and flucythrinate resistance in a horn fly population. J. Agric. Entomol. 1(3), 305.310.

Veterinary Entomology. 2015. Veterinary Parasitology Taylor/Veterinary:161-258.

Walker, F. 1851. Insecta Britanica : Diptera / by Francis Walker.

Wardhaugh, K. G. 2005. Insecticidal Activity Of Synthetic Pyrethroids, Organophosphates, Insect Growth Regulators, And Other Livestock Parasiticides: An Australian Perspective. Environmental Toxicology and Chemistry 24:789.

Williams, R. E. 1985. Livestock entomology. Wiley, New York. 
Williams, R. E., E. J. Westby, K. S. Hendrix, and R. P. Lemenager. 1981. Use of InsecticideImpregnated Ear Tags for the Control of Face Flies and Horn Flies on Pastured Cattle1. J. Anim. Sci. 53:1159-1165.

Wijayaratne, L. K., P. G. Fields, and F. H. Arthur. 2011. Effect of methoprene on the progeny production of Tribolium castaneum (Coleoptera: Tenebrionidae). Pest Management Science 68:217-224. 